\title{
Retinal pigment epithelium cells produce VEGF in response to oxidized phospholipids through mechanisms involving ATF4 and protein kinase CK2
}

Andreas Pollreisz ${ }^{\mathrm{a}}$, Taras Afonyushkin ${ }^{\mathrm{b}}$, Olga V. Oskolkova ${ }^{\mathrm{b}}$, Florian Gruber ${ }^{\mathrm{c}}$, Valery N. Bochkov $^{b}$, Ursula Schmidt-Erfurth ${ }^{a}$

${ }^{\text {a }}$ Department of Ophthalmology and Optometry, Medical University Vienna, Waehringer Guertel 18-20, 1090 Vienna, Austria;

${ }^{\mathrm{b}}$ Department of Vascular Biology and Thrombosis Research, Centre of Physiology and Pharmacology, Medical University Vienna, Schwarzspanierstrasse 17, I, 1090 Vienna, Austria;

${ }^{\mathrm{c}}$ Department of Dermatology, Medical University Vienna, Waehringer Guertel 18-20, 1090 Vienna, Austria;

Corresponding author:

Ursula Schmidt-Erfurth

Department of Ophthalmology and Optometry

Medical University Vienna

Waehringer Guertel 18-20, 1090 Vienna, Austria;

Email: ursula.schmidt-erfurth@meduniwien.ac.at

Phone: +43 1404007931

Word count: 3132

Grant information: The research was funded by the Austrian Science Fund (FWF):

P23016-B11 to T.A., P22267-B11 to O.V.O, and S10713-B13 to V.N.B. 


\begin{abstract}
Oxidized phospholipids (OxPLs) are pleiotropic lipid mediators known to induce proangiogenic and proinflammatory cellular effects that are increasingly recognized to be involved in a number of physiologic and pathologic processes in the retina. Immunohistochemical studies have detected OxPLs in retinal structures, such as retinal pigment epithelium (RPE) or photoreceptor cells. This study analyzed whether OxPLs could play a role in upregulation of VEGF, which is a cause of pathological neovascularization characteristic of eye diseases such as age-related macular degeneration. We confirmed accumulation of OxPLs in the eye using reversed-phase liquid chromatography coupled to mass spectrometry. Multiple species of oxidized phosphatidylcholines (OxPCs) were detected in human vitreous, including biologically active fragmented species POVPC, PGPC, PONPC and PAzPC. In in vitro experiments human fetal RPE and primary RPE cells were stimulated with OxPLs. Primary RPE cells were transfected with small interfering RNAs targeting ATF4. mRNA levels of VEGF in fetal and primary RPE cells were determined by real-time quantitative PCR. VEGF protein concentrations were measured in culture medium by ELISA. We found that OxPCs and other classes of OxPLs upregulated the expression of VEGF in fetal and primary RPE cells, which critically depended on the ATF4. In addition, upregulation of VEGF in primary RPE cells was blocked by a chemical inhibitor of protein kinase CK2 known to suppress induction of ATF4 and VEGF by OxPLs. Our data show that different species of OxPLs, which are present in the human eye are capable of stimulating expression of VEGF in fetal and primary RPE cells via the ATF4-dependent mechanisms.
\end{abstract}

Keywords: oxidized phospholipids, RPE, angiogenesis, unfolded protein response, protein kinase CK2 


\section{Introduction}

The retina, in particular the macular area, is highly susceptible to oxidative damage due to its intensive oxygenation and high levels of polyunsaturated fatty acids. The retinal pigment epithelium (RPE) is a monolayer of cuboidal cells whose apical membrane contacts photoreceptors, while the basolateral membrane is attached to an acellular layer named Bruch membrane. The main functions of the RPE are phagocytosis of photoreceptor outer segments, exchange of retinal between photoreceptors and RPE, transport of nutrients from the choroidal blood to the photoreceptors, removal of waste substances in the opposite direction, and absorption of light. RPE cells also play a major role in the homeostasis of different retinal structures like photoreceptors or choriocapillaries by secreting various growth factors. An important growth factor, which is produced by RPE cells and known to be involved in the pathogenesis of a number of retinal diseases, is vascular endothelial growth factor (VEGF). VEGF is constantly secreted by RPE cells in the healthy eye (Adamis et al., 1993; Lopez et al., 1996; Witmer et al., 2003) mainly to the basolateral side to act on the choroidal endothelium (Becerra et al., 2004; Blaauwgeers et al., 1999). Overexpression of VEGF is a key pathological event in a socioeconomically important disease such as age-related macular degeneration (AMD), which affects millions of people worldwide (de Jong, 2006; Kliffen et al., 1997). Elevated levels of VEGF were detected histologically in the macular area (Kliffen et al., 1997) and in a soluble form in the aqueous humor of eyes with exudative AMD (Funk et al., 2009). To date, treatment is only available for the neovascular form of AMD, and is based on the intravitreal application of antibodies blocking VEGF (Mitchell; Rosenfeld et al., 2006). However, the stimuli leading to enhanced VEGF release from RPE cells and the subsequent neovascularization processes in the choroid are not fully understood (de Jong, 2006). 
Oxidized phospholipids (OxPLs), a certain class of lipid oxidation products, are pleiotropic lipid mediators inducing proinflammatory and angiogenic cellular effects (Bochkov et al., 2010) and have been shown to accumulate in RPE and photoreceptor cells of healthy eyes with increasing levels in older eyes or eyes from AMD patients (Suzuki et al., 2007). Previous studies have shown increased accumulation of OxPLs in RPE and photoreceptor layers or induction of murine choroidal neovascularization by OxPLs in combination with light irradiation (Suzuki et al., 2007; Suzuki et al., 2012). In this work, we present evidence that OxPLs are present in the human vitreous and stimulate the production of VEGF in RPE cells via the ATF4 arm of the unfolded protein response. Furthermore, we identified a chemical CK2 inhibitor, TBB, as a potent agent inhibiting OXPL-induced VEGF upregulation in RPE cells. 


\section{Materials and methods}

\subsection{Fetal human RPE Cell Culture}

Human fetal RPE (fRPE) cells were provided by Dr. Sheldon Miller (National Eye Institute, National Institutes of Health, Bethesda, MD) and cultured in RPE medium, as described previously at $37^{\circ} \mathrm{C}$ and $5 \% \mathrm{CO}_{2}$ (Maminishkis et al., 2006). Cells were used in experiments up to passage 2 .

\subsection{Primary human RPE Cell Culture}

Primary human retinal pigment epithelial cells were purchased from ScienCell (Carlsbad, $\mathrm{CA}$, USA) and cultured at $37^{\circ} \mathrm{C}$ and $5 \% \mathrm{CO}_{2}$ in epithelial cell medium (ScienCell) containing $2 \%$ fetal bovine serum (FBS), epithelial cell growth supplement and penicillin/streptomycin solution (ScienCell). Experiments were performed using cells up to passage 5. RPE cells were stimulated with lipids and other agonists in medium with or without growth factors and antibiotics (as indicated) containing $2 \%$ FBS.

\subsection{Lipids}

Synthetic 1-palmitoyl-2-arachidonoyl-sn-glycero-3-phosphocholine (PAPC) and 1palmitoyl-2-arachidonoyl-sn-glycero-3-phosphoserine (PAPS) were purchased from Avanti Polar Lipids (Alabaster, AL). 1-Palmitoyl-2-azelaoyl-sn-glycero-3-phosphocholine (PAZPC) and 1-palmitoyl-2-(9-oxo)nonanoyl-sn-glycero-3-phosphocholine (PONPC) were obtained from Cayman Chemicals (Ann Arbor, MI). 1-Palmitoyl-2-(5-oxovaleroyl)sn-glycero-3-phosphocholine (POVPC) and 1-palmitoyl-2-glutaroyl-sn-glycero-3phosphocholine (PGPC) were prepared as described previously (Oskolkova et al., 2008). Dry lipids were oxidized by exposure of a thin lipid film to air until approximately $80 \%$ of the lipid was oxidized. Oxidation was monitored by thin-layer chromatography 
and electrospray ionization mass spectrometry (Watson et al., 1997). Oxidized lipids were dissolved in chloroform, purged with argon and stored at $-70^{\circ} \mathrm{C}$. Concentrations of OxPAPC and OxPAPS were determined by phosphorus assay (Broekhuyse, 1968). The dried lipids were resuspended by vigorous vortexing in epithelial cell medium (ScienCell) supplemented with $2 \%$ FBS (ScienCell) before use in cell culture experiments.

\subsection{RNA Isolation, cDNA Synthesis, and Quantitative Real-time Reverse}

\section{Transcription PCR}

Total RNA was isolated using peqGOLD TriFast reagent (Peqlab, Erlangen, Germany) according to the manufacturer's protocol. For mRNA quantification, 900 ng of total RNA was taken for cDNA synthesis using the GeneAmp RNA-PCR kit and oligo $d(T)_{16}$ primers (Applied Biosystems, Foster City, CA). Quantitative real-time PCR (RT-qPCR) was performed using a LightCycler instrument (Roche Diagnostics, Vienna, Austria) and FastStart SYBR Green Master Mix (Roche Diagnostics). Sequences of primers are available on request. All PCR reactions were performed on StepOnePlus Real-Time PCR Cycler (Applied Biosystems).

\section{5. siRNA-mediated Gene Knock-down}

siRNA targeting ATF4 and control siRNA were obtained from Ambion (Brunn am Gebirge, Austria). RPE cells were transfected with $100 \mathrm{nmol} / \mathrm{L}$ of siRNA using RNAiFect Transfection Reagent (QIAGEN, Vienna, Austria) according to the manufacturer's instructions. Forty-eight hours after transfection, the cells were treated with OxPAPC. Efficiency of ATF4 knock-down was confirmed by RT-qPCR analysis of mRNA.

\subsection{Protein kinase CK2 inhibition by TBB}

4,5,6,7-Tetrabromobenzotriazole (TBB) was purchased from Calbiochem (Merck 
Millipore, Darmstadt, Germany). Primary RPE cells were pretreated either with TBB (10 $\mu \mathrm{mol} / \mathrm{l})$ or vehicle for 1 hour followed by addition of OxPAPC (100 $\mu \mathrm{mol} / \mathrm{l})$. Four hours after OxPAPC stimulation peqGOLD TriFast reagent (Peqlab) was added for isolation of RNA. Cell supernatant for protein analysis by ELISA was collected 8 hours after OxPAPC stimulation.

\subsection{Collection of Human Vitreous}

Vitreous fluid samples were collected from 4 eyes of 4 patients with a mean age of $67 \pm 6.1$ years undergoing surgery for the removal of epiretinal membranes at the beginning of the intervention. Vitreous fluid was taken through a one-port system by 23gauge vitrectomy and minimal suction directly into a $2 \mathrm{ml}$ syringe. A minimum volume of $200 \mu \mathrm{L}$ vitreous was taken from each patient. Samples were processed immediately, i.e. antioxidants were added and stored at $-80^{\circ} \mathrm{C}$ until lipid extraction and analysis by mass spectrometry. Informed consent was obtained from the patients before study inclusion. The protocol was approved by the Ethics Committee of the Medical University of Vienna and adhered to the tenets of the Declaration of Helsinki.

\subsection{Enzyme Linked-immunosorbent Assay (ELISA)}

ELISA for detection and quantification of VEGF-A in culture medium conditioned by RPE cells treated with OxPAPC, OxPAPS, fragmented OxPCs (PGPC, PONPC, PAZPC, POVPC) or TBB was purchased from eBioscience (Vienna, Austria) and performed according to the manufacturer's instructions.

\subsection{Mass Spectrometry}

Extraction of lipids and mass spectrometry was performed as described by Gruber et al. (Gruber et al., 2007) on a 4000 Q Trap AB Sciex mass spectrometer 
equipped with an electrospray source.

\subsection{SDS-PAGE and Western blot}

RPE cells were cultured in 12-well plates, stimulated with OxPAPC, Tunicamycin (Tun; Sigma-Aldrich, Vienna, Austria) or left untreated. Nuclear extracts were prepared with “NE-PER Nuclear and Cytoplasmic Extraction Reagents" (Pierce, Thermo Fisher Scientific) and reduced with 0.1 M DL-dithiothreitol (DTT; Sigma-Aldrich, Vienna, Austria). SDS-PAGE was conducted on 10\% gels (GE Amersham Pharmacia Biotech, Uppsala, Switzerland). The proteins were then electrotransferred onto nitrocellulose membranes (Bio-Rad) and detected with the primary antibody CREB-2 (sc-200; 1:300 dilution; Santa Cruz Biotechnology, Dallas, Texas) for detection of ATF4 followed by a secondary anti-rabbit HRP-conjugated antibody (1:10000 dilution; Pierce, Thermo Fisher Scientific). ATF4 protein was detected by chemiluminescence with the ImmunStar ${ }^{\mathrm{TM}}$ Western $C^{\text {тм }}$ Substrate kit (Bio-Rad) according to the manufacturer's instructions. Equal loading of protein was confirmed by the uniform Ponceau S staining pattern of the membrane.

\subsection{Statistical Analysis}

The data are representative of 2 to 3 independent experiments and are expressed as mean \pm SD of triplicate or quadruplicate measurements. The analysis was performed by 2-tailed Student's $t$ test. A probability value below 0.05 was considered as significant. Statistical significance of differences is indicated in the figures as *, while n.s. indicates statistically not significant. 


\section{Results}

\subsection{Biologically Active Fragmented Species of OxPCs are Present in the Human}

\section{Vitreous}

Oxidized phospholipids are generated by enzymatic or non-enzymatic oxidation of esterified fatty acids and are increasingly recognized as pleiotropic lipid mediators inducing a variety of biological effects including pro-angiogenic action (Bochkov et al., 2006). Oxidized phosphatidylcholines (OxPCs) represent the most abundant and beststudied class of OxPLs.

To investigate if fragmented OxPCs species can be found in vivo and thus be of (patho)physiological relevance, we collected human vitreous during surgery followed by quantification by LC-MS/MS of the most characteristic products of oxidation such as oxidatively fragmented OxPCs generated from abundant polyunsaturated PCs containing arachidonoyl or linoleoyl residues at the $s n-2$ and palmitoyl residue at the $s n-$ 1 position of the phospholipid. The analysis revealed the presence of fragmented species POVPC, PGPC, PONPC and PAzPC in the human vitreous (Figure 1).

\subsection{Oxidized Phospholipids Upregulate VEGF in Primary Human RPE Cells}

We further tested if OxPLs can induce expression of VEGF in the highly differentiated fetal human RPE (fRPE) cells. fRPE cells were treated with increasing concentrations of OxPAPC followed by quantification of VEGF mRNA by RT-qPCR. We found a dosedependent increase of VEGF mRNA in the OxPAPC-treated fRPE cells (Figure 2A). Having shown the proangiogenic effect of OxPLs in fRPEs, which are only available in limited quantities, we proceeded by using primary human RPE cells and found similar induction of VEGF in these cells (Figure 2B). In additional experiments a phospholipid containing another polar head group, namely OxPAPS, was used and similar 
upregulation of VEGF was observed (Figure 2C). These data suggest that oxidized fatty acid residues rather than polar head groups represent the major structural determinants of activity. In order to confirm that mRNA elevation is accompanied with VEGF protein secretion, VEGF concentrations were measured by an immune assay in the supernatant of RPE cells after stimulation with OxPAPC and OxPAPS. Indeed, we found statistically significantly higher VEGF concentrations in the treated cells when compared to unstimulated control cells (Figure 3A,B).

OxPAPC represents a complex mixture of oxidized molecules, including esterified and non-esterified species, which can influence gene expression via a variety of receptors and signaling mechanisms (Bochkov et al., 2010). Therefore it was important to show that VEGF can be induced by individual molecular species of OxPCs. To this end, we treated RPE cells with commercially available pure fragmented OxPCs such as PGPC, POVPC, PONPC and PAZPC. All these molecules induced statistically significant increase of VEGF mRNA (Figure 2D) and VEGF protein (Figure 3C).

\subsection{Elevation of Genes Involved in the ATF4 arm of Unfolded Protein Response upon Stimulation with OxPAPC in Human RPE Cells}

We have previously demonstrated that ATF4, which is a major transcription factor mediating the unfolded protein response (UPR), is a key regulator of the VEGF induction in endothelial cells treated with OxPLs (Oskolkova et al., 2008). In this study we tested if OxPAPC leads to induction of ATF4 in primary human RPE cells. To this end, human RPE cells were stimulated with increasing concentrations of OxPAPC, followed by quantification by RT-qPCR of mRNA levels of ATF4 and its downstream genes TRIB and ATF3. Addition of OxPAPC resulted in a dose-dependent increase of mRNA levels of the respective genes (ATF4, TRIB, ATF3) as demonstrated in Figure 4A-C. Treatment with OxPAPC resulted in upregulation of ATF4 protein in RPE cells (Figure 4A inset). 
Furthermore, individual molecular species of OxPCs were also capable of inducing an ATF4 downstream gene, TRIB (Figure 4D).

\subsection{OxPAPC-induced upregulation of VEGF and TRIB is mediated by the ATF4 branch of UPR}

In order to test if ATF4 is functionally important for OxPAPC-induced VEGF upregulation, human RPE cells were transfected with siRNA targeting ATF4 followed by the addition of OxPAPC. The results show that siRNA-mediated knock-down of ATF4 statistically significantly reduced the ability of OxPAPC to induce the expression of VEGF or TRIB mRNA in comparison to cells transfected with control siRNA (Figure 5).

\subsection{CK2 inhibition by TBB inhibits OxPAPC-induced VEGF secretion}

Previous studies have identified the involvement of protein kinase CK2 in OxPL-induced VEGF upregulation in endothelial cells (Afonyushkin et al., 2011). In this study we investigated whether inhibition of CK2 would suppress levels of VEGF in response to OxPAPC in RPE cells. Pretreatment of primary RPE cells with TBB resulted in a significant inhibition of OxPAPC-induced upregulation of VEGF mRNA and protein (Figure 6). 


\section{Discussion}

In our study we have shown the presence of biologically active fragmented species of OxPLs in the human vitreous. Treatment of RPE cells with OxPLs in turn led to the upregulation of VEGF mRNA and protein. Furthermore, we found that the induction of VEGF by OxPLs critically depended on the ATF4 protein, which is considered as an important mediator of the unfolded protein response (UPR). Another major finding of our work is the ability of an inhibitor targeting CK2 to inhibit induction of VEGF in human RPE cells treated with OxPLs.

VEGF is considered a major pathogenic mediator in retinal diseases such as AMD. The importance of VEGF is illustrated by the well-documented efficiency of anti-VEGF antibodies in the treatment of neovascular AMD (Martin et al., 2012). Further progress in treating this condition in a more mechanism-based approach is hampered by our limited knowledge on the sources and molecular mechanisms leading to increased local production of VEGF in the diseased eye.

OxPLs have been localized throughout the healthy retina, in particular photoreceptors, RPE and choroid by immunohistochemistry with increased levels found in older eyes and eyes with AMD (Suzuki et al., 2007). Another support for the (patho)physiological relevance of OxPLs is provided by our data on the presence of these molecular species in the human vitreous in vivo. Despite the various possible points of action of OxPLs in the retina we focused on one single cell type, namely RPE, playing a key role in various retinal diseases. Several studies have suggested a pathological role for OxPLs in patients with AMD by showing increased levels of OxPLs in RPE and photoreceptor cells as compared to age-matched controls. Our finding of OxPLs in the vitreous of eyes with idiopathic ERM points to the existence of another potential pool of OxPLs in the eye. Although the RPE layer is separated from the vitreous by retinal layers, the barrier is 
permeable and thus allows exchange of solutes between RPE and vitreous. This notion is supported by multiple publications showing increased levels of cytokines and growth factors in vitreous of eyes with retinal diseases like epiretinal membranes (ERM), proliferative vitreoretinopathy or diabetic retinopathy (Yoshimura et al., 2009; Pollreisz et al., 2013). We hypothesize that OxPLs present in the vitreous may be a marker of disease reflecting increased oxidation in RPE. On the other hand, OxPLs present in vitreous, independently of their origin, can also act as 'makers' of disease by diffusing to RPE cells and stimulating angiogenic switch, ultimately leading to neovascularization as observed in AMD. Detailed studies of different species of vitreous OxPLs are needed to further elucidate mechanisms of their generation, cellular targets of their action and pathological role in different eye diseases.

Phospholipid oxidation products have been shown to induce production of the proinflammatory and proangiogenic chemokine MCP-1 in RPE cells, which in turn stimulates the secretion of VEGF via an autocrine mode (Suzuki et al., 2012). In contrast, our findings show that different molecular species of OxPCs, as well as oxidized phosphatidylserine, can directly stimulate the secretion of VEGF from RPE cells. Our results provide new insight into molecular mechanisms of increased VEGF production by RPE cells upon stimulation with OxPLs. We identified the ATF4 transcription factor, which is increasingly recognized as an important mediator of pathological angiogenesis (Oskolkova et al., 2008; Roybal et al., 2005; Roybal et al., 2004), as a key regulator of retinal VEGF expression induced by OxPLs. Gargalovic and coworkers demonstrated activation of all three arms of UPR, including IRE1, ATF6 and PERK-ATF4 upon stimulation with OxPLs (Gargalovic et al., 2006). In preliminary experiments we observed only borderline activation of IRE1 and ATF6 upon treatment with OxPLs, while ATF4 showed consistent strong upregulation. Therefore, we limited this study to the role of ATF4. Previously we have shown that ATF4 directly binds to a 
specific site within the VEGF promoter thus stimulating its transcription (Oskolkova et al., 2008).

Protein kinase CK2 is a serine/threonine kinase, which is involved in a number of cellular biological processes including cellular stress reactions (Ahmed et al., 2002; Poole et al., 2005). CK2 is recognized as a major regulator of several signaling pathways involved in angiogenesis (Ljubimov et al., 2004). Our previous data suggest that suppression of CK2 inhibits activation of NRF2 in OxPL-treated cells (Afonyushkin et al., 2011), which in turn prevents induction of ATF4 expression (Afonyushkin et al., 2010). The mechanisms of NRF2 regulation by CK2 are under investigation. It was proposed that CK2 phosphorylates NRF2 inhibitor KEAP-1 leading to stabilization of NRF2 and its binding to ARE promoter sites (Niture et al., 2010). In this work, we used inhibition of CK2 as a tool to show that OxPLs induce VEGF in RPE cells via similar mechanisms, i.e., the CK2ATF4 axis, as was described previously in endothelial cells (Afonyushkin et al., 2011; Afonyushkin et al., 2010; Oskolkova et al., 2008). Tetrabromobenzotriazole (TBB) is a highly selective ATP/GTP-competitive inhibitor of CK2. In a mouse model of oxygeninduced retinal neovascularization intraperitoneal application of TBB alone (Ljubimov et al., 2004) or in combination with a somatostatin analog (Kramerov et al., 2006) resulted in a significant reduction of new vessel growth. Here we show for the first time that OxPL-induced upregulation of VEGF in RPE cells is reversed by treatment of cells with TBB, which suggests TBB as a promising drug inhibiting unwanted VEGF production in the retina.

In summary, our data highlighted potential importance of OxPLs as proangiogenic stimuli in RPE cells and identified the ATF4 protein as a major mediator of increased retinal VEGF production. Furthermore, inhibition of CK2 led to a significantly decreased VEGF production by RPE cells upon OxPL stimulation, thus suggesting that CK2 inhibitors may be applied for therapy of pathological angiogenesis in the eye. 


\section{Financial support}

This work was supported by grants from the Austrian Science Fund (FWF): P23016-B11

to T.A., P22267-B11 to O.V.O, and S10713-B13 to V.N.B.

\section{Disclosure}

The authors have no financial interests to declare.

\section{Acknowledgments}

The authors thank Dr. Sheldon Miller (National Eye Institute, National Institutes of Health, Bethesda, MD) for providing human fetal RPE cells, as well as Dr. Stefan Sacu and Dr. Michael Georgopoulos (Dept. of Ophthalmology and Optometry, Medical University Vienna, Austria) for collecting human vitreous samples. 


\section{References:}

Adamis, A.P., Shima, D.T., Yeo, K.T., Yeo, T.K., Brown, L.F., Berse, B., D'Amore, P.A., Folkman, J., 1993. Synthesis and secretion of vascular permeability factor/vascular endothelial growth factor by human retinal pigment epithelial cells. Biochem. Biophys. Res. Comm. 193, 631-638.

Afonyushkin, T., Oskolkova, O.V., Binder, B.R., Bochkov, V.N., 2011. Involvement of CK2 in activation of electrophilic genes in endothelial cells by oxidized phospholipids. J. Lipid Res. 52, 98-103.

Afonyushkin, T., Oskolkova, O.V., Philippova, M., Resink, T.J., Erne, P., Binder, B.R., Bochkov, V.N., 2010. Oxidized phospholipids regulate expression of ATF4 and VEGF in endothelial cells via NRF2-dependent mechanism: novel point of convergence between electrophilic and unfolded protein stress pathways. Arterioscl. Thromb. Vasc. Biol. 30, 1007-1013.

Ahmed, K., Gerber, D.A., Cochet, C., 2002. Joining the cell survival squad: an emerging role for protein kinase CK2. Trends in Cell Biol. 12, 226-230.

Becerra, S.P., Fariss, R.N., Wu, Y.Q., Montuenga, L.M., Wong, P., Pfeffer, B.A., 2004. Pigment epithelium-derived factor in the monkey retinal pigment epithelium and interphotoreceptor matrix: apical secretion and distribution. Exp. Eye Res. 78, 223-234. Blaauwgeers, H.G., Holtkamp, G.M., Rutten, H., Witmer, A.N., Koolwijk, P., Partanen, T.A., Alitalo, K., Kroon, M.E., Kijlstra, A., van Hinsbergh, V.W., Schlingemann, R.O., 1999. Polarized vascular endothelial growth factor secretion by human retinal pigment epithelium and localization of vascular endothelial growth factor receptors on the inner choriocapillaris. Evidence for a trophic paracrine relation. Am. J. Path. 155, 421-428. Bochkov, V.N., Oskolkova, O.V., Birukov, K.G., Levonen, A.L., Binder, C.J., Stockl, J., 2010. Generation and biological activities of oxidized phospholipids. Antiox. Redox Sign. 12, 1009-1059.

Bochkov, V.N., Philippova, M., Oskolkova, O., Kadl, A., Furnkranz, A., Karabeg, E., Afonyushkin, T., Gruber, F., Breuss, J., Minchenko, A., Mechtcheriakova, D., Hohensinner, P., Rychli, K., Wojta, J., Resink, T., Erne, P., Binder, B.R., Leitinger, N., 2006. Oxidized phospholipids stimulate angiogenesis via autocrine mechanisms, implicating a novel role for lipid oxidation in the evolution of atherosclerotic lesions. Circ. Res. 99, 900-908.

Broekhuyse, R.M., 1968. Phospholipids in tissues of the eye. I. Isolation, characterization and quantitative analysis by two-dimensional thin-layer chromatography of diacyl and vinyl-ether phospholipids. Biochem. et Biophys. Act. 152, 307-315. de Jong, P.T., 2006. Age-related macular degeneration. N. Engl. J. Med. 355, 14741485.

Funk, M., Karl, D., Georgopoulos, M., Benesch, T., Sacu, S., Polak, K., Zlabinger, G.J., Schmidt-Erfurth, U., 2009. Neovascular age-related macular degeneration: intraocular cytokines and growth factors and the influence of therapy with ranibizumab. Ophthalmology 116, 2393-2399.

Gargalovic, P.S., Gharavi, N.M., Clark, M.J., Pagnon, J., Yang, W.P., He, A., Truong, A., Baruch-Oren, T., Berliner, J.A., Kirchgessner, T.G., Lusis, A.J., 2006. The unfolded protein response is an important regulator of inflammatory genes in endothelial cells. Arterioscl. Thromb. Vasc. Biol. 26, 2490-2496.

Gruber, F., Oskolkova, O., Leitner, A., Mildner, M., Mlitz, V., Lengauer, B., Kadl, A., Mrass, P., Kronke, G., Binder, B.R., Bochkov, V.N., Leitinger, N., Tschachler, E., 2007. 
Photooxidation generates biologically active phospholipids that induce heme oxygenase1 in skin cells. J. Biol. Chem. 282, 16934-16941.

Kliffen, M., Sharma, H.S., Mooy, C.M., Kerkvliet, S., de Jong, P.T., 1997. Increased expression of angiogenic growth factors in age-related maculopathy. $\mathrm{Br}$. J. Ophthalmol. 81, 154-162.

Kramerov, A.A., Saghizadeh, M., Pan, H., Kabosova, A., Montenarh, M., Ahmed, K., Penn, J.S., Chan, C.K., Hinton, D.R., Grant, M.B., Ljubimov, A.V., 2006. Expression of protein kinase CK2 in astroglial cells of normal and neovascularized retina. Am. J. Path. $168,1722-1736$.

Ljubimov, A.V., Caballero, S., Aoki, A.M., Pinna, L.A., Grant, M.B., Castellon, R., 2004. Involvement of protein kinase CK2 in angiogenesis and retinal neovascularization. Invest. Ophthalmol. Vis. Sci. 45, 4583-4591.

Lopez, P.F., Sippy, B.D., Lambert, H.M., Thach, A.B., Hinton, D.R., 1996.

Transdifferentiated retinal pigment epithelial cells are immunoreactive for vascular endothelial growth factor in surgically excised age-related macular degeneration-related choroidal neovascular membranes. Invest. Ophthalmol. Vis. Sci. 37, 855-868.

Maminishkis, A., Chen, S., Jalickee, S., Banzon, T., Shi, G., Wang, F.E., Ehalt, T., Hammer, J.A., Miller, S.S., 2006. Confluent monolayers of cultured human fetal retinal pigment epithelium exhibit morphology and physiology of native tissue. Invest.

Ophthalmol. Vis. Sci. 47, 3612-3624.

Martin, D.F., Maguire, M.G., Fine, S.L., Ying, G.S., Jaffe, G.J., Grunwald, J.E., Toth, C., Redford, M., Ferris, F.L., 3rd, 2012. Ranibizumab and bevacizumab for treatment of neovascular age-related macular degeneration: two-year results. Ophthalmology 119 , 1388-1398.

Mitchell, P., 2011. A systematic review of the efficacy and safety outcomes of anti-VEGF agents used for treating neovascular age-related macular degeneration: comparison of ranibizumab and bevacizumab. Current medical research and opinion 27, 1465-1475. Niture, S.K., Jaiswal, A.K. 2010. Hsp90 interaction with INrf2(Keap1) mediates stressinduced Nrf2 activation. J. Biol. Chem. 19, 36865-36875.

Oskolkova, O.V., Afonyushkin, T., Leitner, A., von Schlieffen, E., Gargalovic, P.S., Lusis, A.J., Binder, B.R., Bochkov, V.N., 2008. ATF4-dependent transcription is a key mechanism in VEGF up-regulation by oxidized phospholipids: critical role of oxidized sn2 residues in activation of unfolded protein response. Blood 112, 330-339.

Pollreisz, A., Funk, M., Breitwieser, F.P., Parapatics, K., Sacu, S., Georgopoulos, M., Dunavoelgyi, R., Zlabinger, G.J., Colinge, J., Bennett, K.L., Schmidt-Erfurth, U., 2013. Quantitative proteomics of aqueous and vitreous fluid from patients with idiopathic epiretinal membranes. Exp. Eye Res. 108, 48-58.

Poole, A., Poore, T., Bandhakavi, S., McCann, R.O., Hanna, D.E., Glover, C.V., 2005. A global view of CK2 function and regulation. Mol. and Cell. Biochem. 274, 163-170. Rosenfeld, P.J., Brown, D.M., Heier, J.S., Boyer, D.S., Kaiser, P.K., Chung, C.Y., Kim, R.Y., 2006. Ranibizumab for neovascular age-related macular degeneration. N. Engl. J. Med. 355, 1419-1431.

Roybal, C.N., Hunsaker, L.A., Barbash, O., Vander Jagt, D.L., Abcouwer, S.F., 2005. The oxidative stressor arsenite activates vascular endothelial growth factor mRNA transcription by an ATF4-dependent mechanism. J. Biol. Chem. 280, 20331-20339. Roybal, C.N., Yang, S., Sun, C.W., Hurtado, D., Vander Jagt, D.L., Townes, T.M., Abcouwer, S.F., 2004. Homocysteine increases the expression of vascular endothelial growth factor by a mechanism involving endoplasmic reticulum stress and transcription factor ATF4. J. Biol. Chem. 279, 14844-14852. 
Suzuki, M., Kamei, M., Itabe, H., Yoneda, K., Bando, H., Kume, N., Tano, Y., 2007. Oxidized phospholipids in the macula increase with age and in eyes with age-related macular degeneration. Mol. Vis. 13, 772-778.

Suzuki, M., Tsujikawa, M., Itabe, H., Du, Z.J., Xie, P., Matsumura, N., Fu, X., Zhang, R., Sonoda, K.H., Egashira, K., Hazen, S.L., Kamei, M., 2012. Chronic photo-oxidative stress and subsequent MCP-1 activation as causative factors for age-related macular degeneration. J. Cell Sci. 125, 2407-2415.

Watson, A.D., Leitinger, N., Navab, M., Faull, K.F., Horkko, S., Witztum, J.L., Palinski, W., Schwenke, D., Salomon, R.G., Sha, W., Subbanagounder, G., Fogelman, A.M., Berliner, J.A., 1997. Structural identification by mass spectrometry of oxidized phospholipids in minimally oxidized low density lipoprotein that induce monocyte/endothelial interactions and evidence for their presence in vivo. J. Biol. Chem. 272, 13597-13607.

Witmer, A.N., Vrensen, G.F., Van Noorden, C.J., Schlingemann, R.O., 2003. Vascular endothelial growth factors and angiogenesis in eye disease. Prog. Ret. Eye Res. 22, 129.

Yoshimura, T., Sonoda, K.H., Sugahara, M., Mochizuki, Y., Enaida, H., Oshima, Y., Ueno, A., Hata, Y., Yoshida, H., Ishibashi, T., 2009. Comprehensive analysis of inflammatory immune mediators in vitreoretinal diseases. PLoS One 4, e8158.

Zhang, K., Kaufman, R.J., 2004. Signaling the unfolded protein response from the endoplasmic reticulum. J. Biol. Chem. 279, 25935-25938. 
Figure legends

\section{Figure 1}

Detection of oxidatively fragmented phosphatidylcholines in the human vitreous. Vitreous humor was obtained from 4 eyes of 4 patients with a mean age of $67 \pm 6.1$ years during surgery for the removal of epiretinal membranes in otherwise healthy individuals. Ocular fluid samples were supplemented with antioxidants and processed for lipid extraction and further LC-MS/MS analysis of OxPCs. Representative LC-MS/MS chromatograms show the presence of oxidatively fragmented phosphatidylcholines, including POVPC, PGPC, PONPC, PAzPC in the human vitreous.

\section{Figure 2}

\section{Induction of VEGF in human RPE cells after stimulation with OxPLs.}

(A) Fetal human RPE cells were stimulated 4 hours with increasing concentrations of OxPAPC, while control cells were incubated with medium (see Material and Methods section) alone. $(B, C)$ Primary human RPE cells were treated for 4 hours with increasing concentrations of OxPAPC or OxPAPS in epithelial cell medium containing $2 \%$ FBS. Control cells were incubated with the medium containing no lipids. (D) Human primary RPE cells were treated 4 hours with commercially available pure fragmented OxPCs (PGPC, PONPC, PAzPC, POVPC, each at $50 \mu \mathrm{mol} / \mathrm{L}$ ), while control cells were treated with epithelial cell medium containing $2 \%$ FBS alone. Treatment was stopped by addition of TriFast, followed by RNA extraction and quantification of mRNA from combined quadruplicates by RT-qPCR. VEGF expression levels were normalized to those of $\beta_{2^{-}}$ microglobulin mRNA. Data were obtained in 3 independent experiments. Error bars represent SD. 


\section{Figure 3}

\section{VEGF secretion from human primary RPE cells upon treatment with OxPLs}

$(A, B)$ Human primary RPE cells were incubated for 16 hours in epithelial cell medium containing $2 \%$ FBS and 50 or $100 \mu \mathrm{mol} / \mathrm{L}$ OxPAPC or OxPAPS. (C) In additional experiments human primary RPE cells were treated for 10 hours with pure fragmented OxPCs (PGPC, PONPC, PAzPC, POVPC, each at $50 \mu \mathrm{mol} / \mathrm{L})$. The medium was collected and analyzed for VEGF protein by ELISA. Data were obtained from 2 independent experiments. Error bars represent SD of triplicate measurements.

\section{Figure 4}

Dose-dependent upregulation of UPR genes upon stimulation with OxPAPC.

(A-C) Primary human RPE cells were treated for 4 hours with increasing concentrations of OxPAPC in epithelial cell medium supplemented with $2 \%$ FBS. After aspiration of medium and addition of TriFast, RNA was extracted and mRNA levels of (A) ATF4, (B) TRIB and (C) ATF3 were determined from quadruplicate samples by RT-qPCR. (D) In additional experiments, RPE cells were treated 4 hours with commercially available pure fragmented OxPCs (PGPC, PONPC, PAZPC, POVPC, each at $50 \mu \mathrm{mol} / \mathrm{L}$ ). Stimulation was stopped by Trifast, RNA extracted from quadruplicate samples and TRIB mRNA levels determined by RT-qPCR. The data were normalized to $\beta_{2}$-microglobulin mRNA. Three independent experiments were performed. Error bars represent SD. (Inset A) Treatment of human RPE cells with OxPAPC $(100 \mu \mathrm{mol} / \mathrm{l})$ induces ATF4 protein. RPE cells were treated with OxPAPC (50 or $100 \mu \mathrm{mol} / \mathrm{l}$ ), Tunicamycin (Tun; positive control; $5 \mu \mathrm{g} / \mathrm{mL}$ ) or with medium containing $2 \%$ FBS alone. Six hours after stimulation nuclear cell extracts were prepared and probed with ATF4 antibodies using Western blotting. Blot is representative of 3 independent experiments. 


\section{Figure 5}

\section{ATF4 is involved in OxPAPC-mediated upregulation of VEGF and TRIB.}

Primary human RPE cells were transfected with $100 \mathrm{nmol} / \mathrm{L}$ of siRNA targeting ATF4 or control siRNA. Forty-eight hours after transfection, cells were treated with $100 \mu \mathrm{mol} / \mathrm{L}$ of OxPAPC for 4 hours. Stimulation was stopped by aspiration of medium and addition of TriFast. RNA was extracted and mRNA levels of (A) VEGF, (B) TRIB and (C) ATF4 were measured with RT-qPCR and normalized to $\beta_{2}$-microglobulin. Error bars represent SD of quadruplicate samples. (A, B). * Indicates statistical significance between OxPAPC treated cells transfected with ATF4 siRNA and control cells treated with OxPAPC. (C) * Indicates statistical significance between ATF4 mRNA of cells treated with OxPAPC with and without ATF4 siRNA transfection. No statistical significance was observed between ATF4 siRNA transfected cells when treated with OxPAPC, left untreated or in untreated control siRNA cells. Data were obtained in 3 independent experiments.

\section{Figure 6}

\section{CK2 inhibition by TBB reduces VEGF mRNA expression and protein secretion upon OxPAPC stimulation}

Primary RPE cells were pretreated with either TBB $(10 \mu \mathrm{mol} / \mathrm{L})$ or vehicle for 1 hour and subsequently stimulated with OxPAPC $(100 \mu \mathrm{mol} / \mathrm{L})$. Four hours later the stimulation was stopped by addition of TriFast. VEGF mRNA expression from quadruplicate samples was quantified by real-time qPCR and normalized to $\beta 2$-microglobulin mRNA levels (A). Eight hours after stimulation medium was collected for detection of VEGF protein by ELISA (B). Data were obtained from 3 independent experiments. Error bars represent SD. * Indicates statistical significance of differences between OxPAPCs stimulated cells pretreated with TBB and control cells pretreated with vehicle alone. 


\section{Retinal pigment epithelium cells produce VEGF in response to oxidized phospholipids through mechanisms involving ATF4 and protein kinase CK2}

Andreas Pollreisz ${ }^{\mathrm{a}}$, Taras Afonyushkin ${ }^{\mathrm{b}}$, Olga V. Oskolkova ${ }^{\mathrm{b}}$, Florian Gruber $^{\mathrm{c}}$, Valery N. Bochkov $^{\mathrm{b}}$, Ursula Schmidt-Erfurth ${ }^{\mathrm{a}}$

${ }^{a}$ Department of Ophthalmology and Optometry, Medical University Vienna, Waehringer Guertel 18-20, 1090 Vienna, Austria;

${ }^{\mathrm{b}}$ Department of Vascular Biology and Thrombosis Research, Centre of Physiology and Pharmacology, Medical University Vienna, Schwarzspanierstrasse 17, I, 1090 Vienna, Austria;

${ }^{\mathrm{c}}$ Department of Dermatology, Medical University Vienna, Waehringer Guertel 18-20, 1090 Vienna, Austria;

Corresponding author:

Ursula Schmidt-Erfurth

Department of Ophthalmology and Optometry Medical University Vienna

Waehringer Guertel 18-20, 1090 Vienna, Austria;

Email: ursula.schmidt-erfurth@meduniwien.ac.at

Phone: +43140400 7931

Word count: 3132

Grant information: The research was funded by the Austrian Science Fund (FWF): P23016-B11 to T.A., P22267-B11 to O.V.O, and S10713-B13 to V.N.B. 


\begin{abstract}
Oxidized phospholipids (OxPLs) are pleiotropic lipid mediators known to induce proangiogenic and proinflammatory cellular effects that are increasingly recognized to be involved in a number of physiologic and pathologic processes in the retina. Immunohistochemical studies have detected OxPLs in retinal structures, such as retinal pigment epithelium (RPE) or photoreceptor cells. This study analyzed whether OxPLs could play a role in upregulation of VEGF, which is a cause of pathological neovascularization characteristic of eye diseases such as age-related macular degeneration. We confirmed accumulation of OxPLs in the eye using reversed-phase liquid chromatography coupled to mass spectrometry. Multiple species of oxidized phosphatidylcholines (OxPCs) were detected in human vitreous, including biologically active fragmented species POVPC, PGPC, PONPC and PAzPC. In in vitro experiments human fetal RPE and primary RPE cells were stimulated with OxPLs. Primary RPE cells were transfected with small interfering RNAs targeting ATF4. mRNA levels of VEGF in fetal and primary RPE cells were determined by real-time quantitative PCR. VEGF protein concentrations were measured in culture medium by ELISA. We found that OxPCs and other classes of OxPLs upregulated the expression of VEGF in fetal and primary RPE cells, which critically depended on the ATF4. In addition, upregulation of VEGF in primary RPE cells was blocked by a chemical inhibitor of protein kinase CK2 known to suppress induction of ATF4 and VEGF by OxPLs. Our data show that different species of OxPLs, which are present in the human eye are capable of stimulating expression of VEGF in fetal and primary RPE cells via the ATF4-dependent mechanisms.
\end{abstract}

Keywords: oxidized phospholipids, RPE, angiogenesis, unfolded protein response, protein kinase CK2 


\section{Introduction}

The retina, in particular the macular area, is highly susceptible to oxidative damage due to its intensive oxygenation and high levels of polyunsaturated fatty acids. The retinal pigment epithelium (RPE) is a monolayer of cuboidal cells whose apical membrane contacts photoreceptors, while the basolateral membrane is attached to an acellular layer named Bruch membrane. The main functions of the RPE are phagocytosis of photoreceptor outer segments, exchange of retinal between photoreceptors and RPE, transport of nutrients from the choroidal blood to the photoreceptors, removal of waste substances in the opposite direction, and absorption of light. RPE cells also play a major role in the homeostasis of different retinal structures like photoreceptors or choriocapillaries by secreting various growth factors. An important growth factor, which is produced by RPE cells and known to be involved in the pathogenesis of a number of retinal diseases, is vascular endothelial growth factor (VEGF). VEGF is constantly secreted by RPE cells in the healthy eye (Adamis et al., 1993; Lopez et al., 1996; Witmer et al., 2003) mainly to the basolateral side to act on the choroidal endothelium (Becerra et al., 2004; Blaauwgeers et al., 1999). Overexpression of VEGF is a key pathological event in a socioeconomically important disease such as age-related macular degeneration (AMD), which affects millions of people worldwide (de Jong, 2006; Kliffen et al., 1997). Elevated levels of VEGF were detected histologically in the macular area (Kliffen et al., 1997) and in a soluble form in the aqueous humor of eyes with exudative AMD (Funk et al., 2009). To date, treatment is only available for the neovascular form of AMD, and is based on the intravitreal application of antibodies blocking VEGF (Mitchell; Rosenfeld et al., 2006). However, the stimuli leading to enhanced VEGF release from RPE cells and the subsequent neovascularization processes in the choroid are not fully understood (de Jong, 2006). 
Oxidized phospholipids (OxPLs), a certain class of lipid oxidation products, are pleiotropic lipid mediators inducing proinflammatory and angiogenic cellular effects (Bochkov et al., 2010) and have been shown to accumulate in RPE and photoreceptor cells of healthy eyes with increasing levels in older eyes or eyes from AMD patients (Suzuki et al., 2007). Previous studies have shown increased accumulation of OxPLs in RPE and photoreceptor layers or induction of murine choroidal neovascularization by OxPLs in combination with light irradiation (Suzuki et al., 2007; Suzuki et al., 2012). In this work, we present evidence that OxPLs are present in the human vitreous and stimulate the production of VEGF in RPE cells via the ATF4 arm of the unfolded protein response. Furthermore, we identified a chemical CK2 inhibitor, TBB, as a potent agent inhibiting OXPL-induced VEGF upregulation in RPE cells. 


\section{Materials and methods}

\subsection{Fetal human RPE Cell Culture}

Human fetal RPE (fRPE) cells were provided by Dr. Sheldon Miller (National Eye Institute, National Institutes of Health, Bethesda, MD) and cultured in RPE medium, as described previously at $37^{\circ} \mathrm{C}$ and $5 \% \mathrm{CO}_{2}$ (Maminishkis et al., 2006). Cells were used in experiments up to passage 2 .

\subsection{Primary human RPE Cell Culture}

Primary human retinal pigment epithelial cells were purchased from ScienCell (Carlsbad, $\mathrm{CA}$, USA) and cultured at $37^{\circ} \mathrm{C}$ and $5 \% \mathrm{CO}_{2}$ in epithelial cell medium (ScienCell) containing $2 \%$ fetal bovine serum (FBS), epithelial cell growth supplement and penicillin/streptomycin solution (ScienCell). Experiments were performed using cells up to passage 5. RPE cells were stimulated with lipids and other agonists in medium with or without growth factors and antibiotics (as indicated) containing $2 \%$ FBS.

\subsection{Lipids}

Synthetic 1-palmitoyl-2-arachidonoyl-sn-glycero-3-phosphocholine (PAPC) and 1palmitoyl-2-arachidonoyl-sn-glycero-3-phosphoserine (PAPS) were purchased from Avanti Polar Lipids (Alabaster, AL). 1-Palmitoyl-2-azelaoyl-sn-glycero-3-phosphocholine (PAZPC) and 1-palmitoyl-2-(9-oxo)nonanoyl-sn-glycero-3-phosphocholine (PONPC) were obtained from Cayman Chemicals (Ann Arbor, MI). 1-Palmitoyl-2-(5-oxovaleroyl)sn-glycero-3-phosphocholine (POVPC) and 1-palmitoyl-2-glutaroyl-sn-glycero-3phosphocholine (PGPC) were prepared as described previously (Oskolkova et al., 2008). Dry lipids were oxidized by exposure of a thin lipid film to air until approximately $80 \%$ of the lipid was oxidized. Oxidation was monitored by thin-layer chromatography 
and electrospray ionization mass spectrometry (Watson et al., 1997). Oxidized lipids were dissolved in chloroform, purged with argon and stored at $-70^{\circ} \mathrm{C}$. Concentrations of OxPAPC and OxPAPS were determined by phosphorus assay (Broekhuyse, 1968). The dried lipids were resuspended by vigorous vortexing in epithelial cell medium (ScienCell) supplemented with $2 \%$ FBS (ScienCell) before use in cell culture experiments.

\subsection{RNA Isolation, cDNA Synthesis, and Quantitative Real-time Reverse}

\section{Transcription PCR}

Total RNA was isolated using peqGOLD TriFast reagent (Peqlab, Erlangen, Germany) according to the manufacturer's protocol. For mRNA quantification, 900 ng of total RNA was taken for cDNA synthesis using the GeneAmp RNA-PCR kit and oligo $d(T)_{16}$ primers (Applied Biosystems, Foster City, CA). Quantitative real-time PCR (RT-qPCR) was performed using a LightCycler instrument (Roche Diagnostics, Vienna, Austria) and FastStart SYBR Green Master Mix (Roche Diagnostics). Sequences of primers are available on request. All PCR reactions were performed on StepOnePlus Real-Time PCR Cycler (Applied Biosystems).

\section{5. siRNA-mediated Gene Knock-down}

siRNA targeting ATF4 and control siRNA were obtained from Ambion (Brunn am Gebirge, Austria). RPE cells were transfected with $100 \mathrm{nmol} / \mathrm{L}$ of siRNA using RNAiFect Transfection Reagent (QIAGEN, Vienna, Austria) according to the manufacturer's instructions. Forty-eight hours after transfection, the cells were treated with OxPAPC. Efficiency of ATF4 knock-down was confirmed by RT-qPCR analysis of mRNA.

\subsection{Protein kinase CK2 inhibition by TBB}

4,5,6,7-Tetrabromobenzotriazole (TBB) was purchased from Calbiochem (Merck 
Millipore, Darmstadt, Germany). Primary RPE cells were pretreated either with TBB (10 $\mu \mathrm{mol} / \mathrm{l})$ or vehicle for 1 hour followed by addition of OxPAPC (100 $\mu \mathrm{mol} / \mathrm{l})$. Four hours after OxPAPC stimulation peqGOLD TriFast reagent (Peqlab) was added for isolation of RNA. Cell supernatant for protein analysis by ELISA was collected 8 hours after OxPAPC stimulation.

\subsection{Collection of Human Vitreous}

Vitreous fluid samples were collected from 4 eyes of 4 patients with a mean age of $67 \pm 6.1$ years undergoing surgery for the removal of epiretinal membranes at the beginning of the intervention. Vitreous fluid was taken through a one-port system by 23gauge vitrectomy and minimal suction directly into a $2 \mathrm{ml}$ syringe. A minimum volume of $200 \mu \mathrm{L}$ vitreous was taken from each patient. Samples were processed immediately, i.e. antioxidants were added and stored at $-80^{\circ} \mathrm{C}$ until lipid extraction and analysis by mass spectrometry. Informed consent was obtained from the patients before study inclusion. The protocol was approved by the Ethics Committee of the Medical University of Vienna and adhered to the tenets of the Declaration of Helsinki.

\subsection{Enzyme Linked-immunosorbent Assay (ELISA)}

ELISA for detection and quantification of VEGF-A in culture medium conditioned by RPE cells treated with OxPAPC, OxPAPS, fragmented OxPCs (PGPC, PONPC, PAZPC, POVPC) or TBB was purchased from eBioscience (Vienna, Austria) and performed according to the manufacturer's instructions.

\subsection{Mass Spectrometry}

Extraction of lipids and mass spectrometry was performed as described by Gruber et al. (Gruber et al., 2007) on a 4000 Q Trap AB Sciex mass spectrometer 
equipped with an electrospray source.

\subsection{SDS-PAGE and Western blot}

RPE cells were cultured in 12-well plates, stimulated with OxPAPC, Tunicamycin (Tun; Sigma-Aldrich, Vienna, Austria) or left untreated. Nuclear extracts were prepared with “NE-PER Nuclear and Cytoplasmic Extraction Reagents" (Pierce, Thermo Fisher Scientific) and reduced with 0.1 M DL-dithiothreitol (DTT; Sigma-Aldrich, Vienna, Austria). SDS-PAGE was conducted on 10\% gels (GE Amersham Pharmacia Biotech, Uppsala, Switzerland). The proteins were then electrotransferred onto nitrocellulose membranes (Bio-Rad) and detected with the primary antibody CREB-2 (sc-200; 1:300 dilution; Santa Cruz Biotechnology, Dallas, Texas) for detection of ATF4 followed by a secondary anti-rabbit HRP-conjugated antibody (1:10000 dilution; Pierce, Thermo Fisher Scientific). ATF4 protein was detected by chemiluminescence with the ImmunStar ${ }^{\mathrm{TM}}$ Western $C^{\text {тм }}$ Substrate kit (Bio-Rad) according to the manufacturer's instructions. Equal loading of protein was confirmed by the uniform Ponceau S staining pattern of the membrane.

\subsection{Statistical Analysis}

The data are representative of 2 to 3 independent experiments and are expressed as mean \pm SD of triplicate or quadruplicate measurements. The analysis was performed by 2-tailed Student's $t$ test. A probability value below 0.05 was considered as significant. Statistical significance of differences is indicated in the figures as *, while n.s. indicates statistically not significant. 


\section{Results}

\subsection{Biologically Active Fragmented Species of OxPCs are Present in the Human}

\section{Vitreous}

Oxidized phospholipids are generated by enzymatic or non-enzymatic oxidation of esterified fatty acids and are increasingly recognized as pleiotropic lipid mediators inducing a variety of biological effects including pro-angiogenic action (Bochkov et al., 2006). Oxidized phosphatidylcholines (OxPCs) represent the most abundant and beststudied class of OxPLs.

To investigate if fragmented OxPCs species can be found in vivo and thus be of (patho)physiological relevance, we collected human vitreous during surgery followed by quantification by LC-MS/MS of the most characteristic products of oxidation such as oxidatively fragmented OxPCs generated from abundant polyunsaturated PCs containing arachidonoyl or linoleoyl residues at the $s n-2$ and palmitoyl residue at the $s n-$ 1 position of the phospholipid. The analysis revealed the presence of fragmented species POVPC, PGPC, PONPC and PAzPC in the human vitreous (Figure 1).

\subsection{Oxidized Phospholipids Upregulate VEGF in Primary Human RPE Cells}

We further tested if OxPLs can induce expression of VEGF in the highly differentiated fetal human RPE (fRPE) cells. fRPE cells were treated with increasing concentrations of OxPAPC followed by quantification of VEGF mRNA by RT-qPCR. We found a dosedependent increase of VEGF mRNA in the OxPAPC-treated fRPE cells (Figure 2A). Having shown the proangiogenic effect of OxPLs in fRPEs, which are only available in limited quantities, we proceeded by using primary human RPE cells and found similar induction of VEGF in these cells (Figure 2B). In additional experiments a phospholipid containing another polar head group, namely OxPAPS, was used and similar 
upregulation of VEGF was observed (Figure 2C). These data suggest that oxidized fatty acid residues rather than polar head groups represent the major structural determinants of activity. In order to confirm that mRNA elevation is accompanied with VEGF protein secretion, VEGF concentrations were measured by an immune assay in the supernatant of RPE cells after stimulation with OxPAPC and OxPAPS. Indeed, we found statistically significantly higher VEGF concentrations in the treated cells when compared to unstimulated control cells (Figure 3A,B).

OxPAPC represents a complex mixture of oxidized molecules, including esterified and non-esterified species, which can influence gene expression via a variety of receptors and signaling mechanisms (Bochkov et al., 2010). Therefore it was important to show that VEGF can be induced by individual molecular species of OxPCs. To this end, we treated RPE cells with commercially available pure fragmented OxPCs such as PGPC, POVPC, PONPC and PAZPC. All these molecules induced statistically significant increase of VEGF mRNA (Figure 2D) and VEGF protein (Figure 3C).

\subsection{Elevation of Genes Involved in the ATF4 arm of Unfolded Protein Response upon Stimulation with OxPAPC in Human RPE Cells}

We have previously demonstrated that ATF4, which is a major transcription factor mediating the unfolded protein response (UPR), is a key regulator of the VEGF induction in endothelial cells treated with OxPLs (Oskolkova et al., 2008). In this study we tested if OxPAPC leads to induction of ATF4 in primary human RPE cells. To this end, human RPE cells were stimulated with increasing concentrations of OxPAPC, followed by quantification by RT-qPCR of mRNA levels of ATF4 and its downstream genes TRIB and ATF3. Addition of OxPAPC resulted in a dose-dependent increase of mRNA levels of the respective genes (ATF4, TRIB, ATF3) as demonstrated in Figure 4A-C. Treatment with OxPAPC resulted in upregulation of ATF4 protein in RPE cells (Figure 4A inset). 
Furthermore, individual molecular species of OxPCs were also capable of inducing an ATF4 downstream gene, TRIB (Figure 4D).

\subsection{OxPAPC-induced upregulation of VEGF and TRIB is mediated by the ATF4 branch of UPR}

In order to test if ATF4 is functionally important for OxPAPC-induced VEGF upregulation, human RPE cells were transfected with siRNA targeting ATF4 followed by the addition of OxPAPC. The results show that siRNA-mediated knock-down of ATF4 statistically significantly reduced the ability of OxPAPC to induce the expression of VEGF or TRIB mRNA in comparison to cells transfected with control siRNA (Figure 5).

\subsection{CK2 inhibition by TBB inhibits OxPAPC-induced VEGF secretion}

Previous studies have identified the involvement of protein kinase CK2 in OxPL-induced VEGF upregulation in endothelial cells (Afonyushkin et al., 2011). In this study we investigated whether inhibition of CK2 would suppress levels of VEGF in response to OxPAPC in RPE cells. Pretreatment of primary RPE cells with TBB resulted in a significant inhibition of OxPAPC-induced upregulation of VEGF mRNA and protein (Figure 6). 


\section{Discussion}

In our study we have shown the presence of biologically active fragmented species of OxPLs in the human vitreous. Treatment of RPE cells with OxPLs in turn led to the upregulation of VEGF mRNA and protein. Furthermore, we found that the induction of VEGF by OxPLs critically depended on the ATF4 protein, which is considered as an important mediator of the unfolded protein response (UPR). Another major finding of our work is the ability of an inhibitor targeting CK2 to inhibit induction of VEGF in human RPE cells treated with OxPLs.

VEGF is considered a major pathogenic mediator in retinal diseases such as AMD. The importance of VEGF is illustrated by the well-documented efficiency of anti-VEGF antibodies in the treatment of neovascular AMD (Martin et al., 2012). Further progress in treating this condition in a more mechanism-based approach is hampered by our limited knowledge on the sources and molecular mechanisms leading to increased local production of VEGF in the diseased eye.

OxPLs have been localized throughout the healthy retina, in particular photoreceptors, RPE and choroid by immunohistochemistry with increased levels found in older eyes and eyes with AMD (Suzuki et al., 2007). Another support for the (patho)physiological relevance of OxPLs is provided by our data on the presence of these molecular species in the human vitreous in vivo. Despite the various possible points of action of OxPLs in the retina we focused on one single cell type, namely RPE, playing a key role in various retinal diseases. Several studies have suggested a pathological role for OxPLs in patients with AMD by showing increased levels of OxPLs in RPE and photoreceptor cells as compared to age-matched controls. Our finding of OxPLs in the vitreous of eyes with idiopathic ERM points to the existence of another potential pool of OxPLs in the eye. Although the RPE layer is separated from the vitreous by retinal layers, the barrier is 
permeable and thus allows exchange of solutes between RPE and vitreous. This notion is supported by multiple publications showing increased levels of cytokines and growth factors in vitreous of eyes with retinal diseases like epiretinal membranes (ERM), proliferative vitreoretinopathy or diabetic retinopathy (Yoshimura et al., 2009; Pollreisz et al., 2013). We hypothesize that OxPLs present in the vitreous may be a marker of disease reflecting increased oxidation in RPE. On the other hand, OxPLs present in vitreous, independently of their origin, can also act as 'makers' of disease by diffusing to RPE cells and stimulating angiogenic switch, ultimately leading to neovascularization as observed in AMD. Detailed studies of different species of vitreous OxPLs are needed to further elucidate mechanisms of their generation, cellular targets of their action and pathological role in different eye diseases.

Phospholipid oxidation products have been shown to induce production of the proinflammatory and proangiogenic chemokine MCP-1 in RPE cells, which in turn stimulates the secretion of VEGF via an autocrine mode (Suzuki et al., 2012). In contrast, our findings show that different molecular species of OxPCs, as well as oxidized phosphatidylserine, can directly stimulate the secretion of VEGF from RPE cells. Our results provide new insight into molecular mechanisms of increased VEGF production by RPE cells upon stimulation with OxPLs. We identified the ATF4 transcription factor, which is increasingly recognized as an important mediator of pathological angiogenesis (Oskolkova et al., 2008; Roybal et al., 2005; Roybal et al., 2004), as a key regulator of retinal VEGF expression induced by OxPLs. Gargalovic and coworkers demonstrated activation of all three arms of UPR, including IRE1, ATF6 and PERK-ATF4 upon stimulation with OxPLs (Gargalovic et al., 2006). In preliminary experiments we observed only borderline activation of IRE1 and ATF6 upon treatment with OxPLs, while ATF4 showed consistent strong upregulation. Therefore, we limited this study to the role of ATF4. Previously we have shown that ATF4 directly binds to a 
specific site within the VEGF promoter thus stimulating its transcription (Oskolkova et al., 2008).

Protein kinase CK2 is a serine/threonine kinase, which is involved in a number of cellular biological processes including cellular stress reactions (Ahmed et al., 2002; Poole et al., 2005). CK2 is recognized as a major regulator of several signaling pathways involved in angiogenesis (Ljubimov et al., 2004). Our previous data suggest that suppression of CK2 inhibits activation of NRF2 in OxPL-treated cells (Afonyushkin et al., 2011), which in turn prevents induction of ATF4 expression (Afonyushkin et al., 2010). The mechanisms of NRF2 regulation by CK2 are under investigation. It was proposed that CK2 phosphorylates NRF2 inhibitor KEAP-1 leading to stabilization of NRF2 and its binding to ARE promoter sites (Niture et al., 2010). In this work, we used inhibition of CK2 as a tool to show that OxPLs induce VEGF in RPE cells via similar mechanisms, i.e., the CK2ATF4 axis, as was described previously in endothelial cells (Afonyushkin et al., 2011; Afonyushkin et al., 2010; Oskolkova et al., 2008). Tetrabromobenzotriazole (TBB) is a highly selective ATP/GTP-competitive inhibitor of CK2. In a mouse model of oxygeninduced retinal neovascularization intraperitoneal application of TBB alone (Ljubimov et al., 2004) or in combination with a somatostatin analog (Kramerov et al., 2006) resulted in a significant reduction of new vessel growth. Here we show for the first time that OxPL-induced upregulation of VEGF in RPE cells is reversed by treatment of cells with TBB, which suggests TBB as a promising drug inhibiting unwanted VEGF production in the retina.

In summary, our data highlighted potential importance of OxPLs as proangiogenic stimuli in RPE cells and identified the ATF4 protein as a major mediator of increased retinal VEGF production. Furthermore, inhibition of CK2 led to a significantly decreased VEGF production by RPE cells upon OxPL stimulation, thus suggesting that CK2 inhibitors may be applied for therapy of pathological angiogenesis in the eye. 


\section{Financial support}

This work was supported by grants from the Austrian Science Fund (FWF): P23016-B11 to T.A., P22267-B11 to O.V.O, and S10713-B13 to V.N.B.

\section{Disclosure}

The authors have no financial interests to declare.

\section{Acknowledgments}

The authors thank Dr. Sheldon Miller (National Eye Institute, National Institutes of Health, Bethesda, MD) for providing human fetal RPE cells, as well as Dr. Stefan Sacu and Dr. Michael Georgopoulos (Dept. of Ophthalmology and Optometry, Medical University Vienna, Austria) for collecting human vitreous samples. 


\section{References:}

Adamis, A.P., Shima, D.T., Yeo, K.T., Yeo, T.K., Brown, L.F., Berse, B., D'Amore, P.A., Folkman, J., 1993. Synthesis and secretion of vascular permeability factor/vascular endothelial growth factor by human retinal pigment epithelial cells. Biochem. Biophys. Res. Comm. 193, 631-638.

Afonyushkin, T., Oskolkova, O.V., Binder, B.R., Bochkov, V.N., 2011. Involvement of CK2 in activation of electrophilic genes in endothelial cells by oxidized phospholipids. J. Lipid Res. 52, 98-103.

Afonyushkin, T., Oskolkova, O.V., Philippova, M., Resink, T.J., Erne, P., Binder, B.R., Bochkov, V.N., 2010. Oxidized phospholipids regulate expression of ATF4 and VEGF in endothelial cells via NRF2-dependent mechanism: novel point of convergence between electrophilic and unfolded protein stress pathways. Arterioscl. Thromb. Vasc. Biol. 30, 1007-1013.

Ahmed, K., Gerber, D.A., Cochet, C., 2002. Joining the cell survival squad: an emerging role for protein kinase CK2. Trends in Cell Biol. 12, 226-230.

Becerra, S.P., Fariss, R.N., Wu, Y.Q., Montuenga, L.M., Wong, P., Pfeffer, B.A., 2004. Pigment epithelium-derived factor in the monkey retinal pigment epithelium and interphotoreceptor matrix: apical secretion and distribution. Exp. Eye Res. 78, 223-234. Blaauwgeers, H.G., Holtkamp, G.M., Rutten, H., Witmer, A.N., Koolwijk, P., Partanen, T.A., Alitalo, K., Kroon, M.E., Kijlstra, A., van Hinsbergh, V.W., Schlingemann, R.O., 1999. Polarized vascular endothelial growth factor secretion by human retinal pigment epithelium and localization of vascular endothelial growth factor receptors on the inner choriocapillaris. Evidence for a trophic paracrine relation. Am. J. Path. 155, 421-428. Bochkov, V.N., Oskolkova, O.V., Birukov, K.G., Levonen, A.L., Binder, C.J., Stockl, J., 2010. Generation and biological activities of oxidized phospholipids. Antiox. Redox Sign. 12, 1009-1059.

Bochkov, V.N., Philippova, M., Oskolkova, O., Kadl, A., Furnkranz, A., Karabeg, E., Afonyushkin, T., Gruber, F., Breuss, J., Minchenko, A., Mechtcheriakova, D., Hohensinner, P., Rychli, K., Wojta, J., Resink, T., Erne, P., Binder, B.R., Leitinger, N., 2006. Oxidized phospholipids stimulate angiogenesis via autocrine mechanisms, implicating a novel role for lipid oxidation in the evolution of atherosclerotic lesions. Circ. Res. 99, 900-908.

Broekhuyse, R.M., 1968. Phospholipids in tissues of the eye. I. Isolation, characterization and quantitative analysis by two-dimensional thin-layer chromatography of diacyl and vinyl-ether phospholipids. Biochem. et Biophys. Act. 152, 307-315. de Jong, P.T., 2006. Age-related macular degeneration. N. Engl. J. Med. 355, 14741485.

Funk, M., Karl, D., Georgopoulos, M., Benesch, T., Sacu, S., Polak, K., Zlabinger, G.J., Schmidt-Erfurth, U., 2009. Neovascular age-related macular degeneration: intraocular cytokines and growth factors and the influence of therapy with ranibizumab. Ophthalmology 116, 2393-2399.

Gargalovic, P.S., Gharavi, N.M., Clark, M.J., Pagnon, J., Yang, W.P., He, A., Truong, A., Baruch-Oren, T., Berliner, J.A., Kirchgessner, T.G., Lusis, A.J., 2006. The unfolded protein response is an important regulator of inflammatory genes in endothelial cells. Arterioscl. Thromb. Vasc. Biol. 26, 2490-2496.

Gruber, F., Oskolkova, O., Leitner, A., Mildner, M., Mlitz, V., Lengauer, B., Kadl, A., Mrass, P., Kronke, G., Binder, B.R., Bochkov, V.N., Leitinger, N., Tschachler, E., 2007. 
Photooxidation generates biologically active phospholipids that induce heme oxygenase1 in skin cells. J. Biol. Chem. 282, 16934-16941.

Kliffen, M., Sharma, H.S., Mooy, C.M., Kerkvliet, S., de Jong, P.T., 1997. Increased expression of angiogenic growth factors in age-related maculopathy. $\mathrm{Br}$. J. Ophthalmol. 81, 154-162.

Kramerov, A.A., Saghizadeh, M., Pan, H., Kabosova, A., Montenarh, M., Ahmed, K., Penn, J.S., Chan, C.K., Hinton, D.R., Grant, M.B., Ljubimov, A.V., 2006. Expression of protein kinase CK2 in astroglial cells of normal and neovascularized retina. Am. J. Path. $168,1722-1736$.

Ljubimov, A.V., Caballero, S., Aoki, A.M., Pinna, L.A., Grant, M.B., Castellon, R., 2004. Involvement of protein kinase CK2 in angiogenesis and retinal neovascularization. Invest. Ophthalmol. Vis. Sci. 45, 4583-4591.

Lopez, P.F., Sippy, B.D., Lambert, H.M., Thach, A.B., Hinton, D.R., 1996.

Transdifferentiated retinal pigment epithelial cells are immunoreactive for vascular endothelial growth factor in surgically excised age-related macular degeneration-related choroidal neovascular membranes. Invest. Ophthalmol. Vis. Sci. 37, 855-868.

Maminishkis, A., Chen, S., Jalickee, S., Banzon, T., Shi, G., Wang, F.E., Ehalt, T., Hammer, J.A., Miller, S.S., 2006. Confluent monolayers of cultured human fetal retinal pigment epithelium exhibit morphology and physiology of native tissue. Invest.

Ophthalmol. Vis. Sci. 47, 3612-3624.

Martin, D.F., Maguire, M.G., Fine, S.L., Ying, G.S., Jaffe, G.J., Grunwald, J.E., Toth, C., Redford, M., Ferris, F.L., 3rd, 2012. Ranibizumab and bevacizumab for treatment of neovascular age-related macular degeneration: two-year results. Ophthalmology 119 , 1388-1398.

Mitchell, P., 2011. A systematic review of the efficacy and safety outcomes of anti-VEGF agents used for treating neovascular age-related macular degeneration: comparison of ranibizumab and bevacizumab. Current medical research and opinion 27, 1465-1475. Niture, S.K., Jaiswal, A.K. 2010. Hsp90 interaction with INrf2(Keap1) mediates stressinduced Nrf2 activation. J. Biol. Chem. 19, 36865-36875.

Oskolkova, O.V., Afonyushkin, T., Leitner, A., von Schlieffen, E., Gargalovic, P.S., Lusis, A.J., Binder, B.R., Bochkov, V.N., 2008. ATF4-dependent transcription is a key mechanism in VEGF up-regulation by oxidized phospholipids: critical role of oxidized sn2 residues in activation of unfolded protein response. Blood 112, 330-339.

Pollreisz, A., Funk, M., Breitwieser, F.P., Parapatics, K., Sacu, S., Georgopoulos, M., Dunavoelgyi, R., Zlabinger, G.J., Colinge, J., Bennett, K.L., Schmidt-Erfurth, U., 2013. Quantitative proteomics of aqueous and vitreous fluid from patients with idiopathic epiretinal membranes. Exp. Eye Res. 108, 48-58.

Poole, A., Poore, T., Bandhakavi, S., McCann, R.O., Hanna, D.E., Glover, C.V., 2005. A global view of CK2 function and regulation. Mol. and Cell. Biochem. 274, 163-170. Rosenfeld, P.J., Brown, D.M., Heier, J.S., Boyer, D.S., Kaiser, P.K., Chung, C.Y., Kim, R.Y., 2006. Ranibizumab for neovascular age-related macular degeneration. N. Engl. J. Med. 355, 1419-1431.

Roybal, C.N., Hunsaker, L.A., Barbash, O., Vander Jagt, D.L., Abcouwer, S.F., 2005. The oxidative stressor arsenite activates vascular endothelial growth factor mRNA transcription by an ATF4-dependent mechanism. J. Biol. Chem. 280, 20331-20339. Roybal, C.N., Yang, S., Sun, C.W., Hurtado, D., Vander Jagt, D.L., Townes, T.M., Abcouwer, S.F., 2004. Homocysteine increases the expression of vascular endothelial growth factor by a mechanism involving endoplasmic reticulum stress and transcription factor ATF4. J. Biol. Chem. 279, 14844-14852. 
Suzuki, M., Kamei, M., Itabe, H., Yoneda, K., Bando, H., Kume, N., Tano, Y., 2007. Oxidized phospholipids in the macula increase with age and in eyes with age-related macular degeneration. Mol. Vis. 13, 772-778.

Suzuki, M., Tsujikawa, M., Itabe, H., Du, Z.J., Xie, P., Matsumura, N., Fu, X., Zhang, R., Sonoda, K.H., Egashira, K., Hazen, S.L., Kamei, M., 2012. Chronic photo-oxidative stress and subsequent MCP-1 activation as causative factors for age-related macular degeneration. J. Cell Sci. 125, 2407-2415.

Watson, A.D., Leitinger, N., Navab, M., Faull, K.F., Horkko, S., Witztum, J.L., Palinski, W., Schwenke, D., Salomon, R.G., Sha, W., Subbanagounder, G., Fogelman, A.M., Berliner, J.A., 1997. Structural identification by mass spectrometry of oxidized phospholipids in minimally oxidized low density lipoprotein that induce monocyte/endothelial interactions and evidence for their presence in vivo. J. Biol. Chem. 272, 13597-13607.

Witmer, A.N., Vrensen, G.F., Van Noorden, C.J., Schlingemann, R.O., 2003. Vascular endothelial growth factors and angiogenesis in eye disease. Prog. Ret. Eye Res. 22, 129.

Yoshimura, T., Sonoda, K.H., Sugahara, M., Mochizuki, Y., Enaida, H., Oshima, Y., Ueno, A., Hata, Y., Yoshida, H., Ishibashi, T., 2009. Comprehensive analysis of inflammatory immune mediators in vitreoretinal diseases. PLoS One 4, e8158.

Zhang, K., Kaufman, R.J., 2004. Signaling the unfolded protein response from the endoplasmic reticulum. J. Biol. Chem. 279, 25935-25938. 
Figure legends

\section{Figure 1}

Detection of oxidatively fragmented phosphatidylcholines in the human vitreous. Vitreous humor was obtained from 4 eyes of 4 patients with a mean age of $67 \pm 6.1$ years during surgery for the removal of epiretinal membranes in otherwise healthy individuals. Ocular fluid samples were supplemented with antioxidants and processed for lipid extraction and further LC-MS/MS analysis of OxPCs. Representative LC-MS/MS chromatograms show the presence of oxidatively fragmented phosphatidylcholines, including POVPC, PGPC, PONPC, PAzPC in the human vitreous.

\section{Figure 2}

\section{Induction of VEGF in human RPE cells after stimulation with OxPLs.}

(A) Fetal human RPE cells were stimulated 4 hours with increasing concentrations of OxPAPC, while control cells were incubated with medium (see Material and Methods section) alone. $(B, C)$ Primary human RPE cells were treated for 4 hours with increasing concentrations of OxPAPC or OxPAPS in epithelial cell medium containing $2 \%$ FBS. Control cells were incubated with the medium containing no lipids. (D) Human primary RPE cells were treated 4 hours with commercially available pure fragmented OxPCs (PGPC, PONPC, PAzPC, POVPC, each at $50 \mu \mathrm{mol} / \mathrm{L}$ ), while control cells were treated with epithelial cell medium containing $2 \%$ FBS alone. Treatment was stopped by addition of TriFast, followed by RNA extraction and quantification of mRNA from combined quadruplicates by RT-qPCR. VEGF expression levels were normalized to those of $\beta_{2^{-}}$ microglobulin mRNA. Data were obtained in 3 independent experiments. Error bars represent SD. 


\section{Figure 3}

\section{VEGF secretion from human primary RPE cells upon treatment with OxPLs}

$(A, B)$ Human primary RPE cells were incubated for 16 hours in epithelial cell medium containing $2 \%$ FBS and 50 or $100 \mu \mathrm{mol} / \mathrm{L}$ OxPAPC or OxPAPS. (C) In additional experiments human primary RPE cells were treated for 10 hours with pure fragmented OxPCs (PGPC, PONPC, PAzPC, POVPC, each at $50 \mu \mathrm{mol} / \mathrm{L})$. The medium was collected and analyzed for VEGF protein by ELISA. Data were obtained from 2 independent experiments. Error bars represent SD of triplicate measurements.

\section{Figure 4}

Dose-dependent upregulation of UPR genes upon stimulation with OxPAPC.

(A-C) Primary human RPE cells were treated for 4 hours with increasing concentrations of OxPAPC in epithelial cell medium supplemented with $2 \%$ FBS. After aspiration of medium and addition of TriFast, RNA was extracted and mRNA levels of (A) ATF4, (B) TRIB and (C) ATF3 were determined from quadruplicate samples by RT-qPCR. (D) In additional experiments, RPE cells were treated 4 hours with commercially available pure fragmented OxPCs (PGPC, PONPC, PAZPC, POVPC, each at $50 \mu \mathrm{mol} / \mathrm{L}$ ). Stimulation was stopped by Trifast, RNA extracted from quadruplicate samples and TRIB mRNA levels determined by RT-qPCR. The data were normalized to $\beta_{2}$-microglobulin mRNA. Three independent experiments were performed. Error bars represent SD. (Inset A) Treatment of human RPE cells with OxPAPC $(100 \mu \mathrm{mol} / \mathrm{l})$ induces ATF4 protein. RPE cells were treated with OxPAPC (50 or $100 \mu \mathrm{mol} / \mathrm{l}$ ), Tunicamycin (Tun; positive control; $5 \mu \mathrm{g} / \mathrm{mL}$ ) or with medium containing $2 \%$ FBS alone. Six hours after stimulation nuclear cell extracts were prepared and probed with ATF4 antibodies using Western blotting. Blot is representative of 3 independent experiments. 


\section{Figure 5}

\section{ATF4 is involved in OxPAPC-mediated upregulation of VEGF and TRIB.}

Primary human RPE cells were transfected with $100 \mathrm{nmol} / \mathrm{L}$ of siRNA targeting ATF4 or control siRNA. Forty-eight hours after transfection, cells were treated with $100 \mu \mathrm{mol} / \mathrm{L}$ of OxPAPC for 4 hours. Stimulation was stopped by aspiration of medium and addition of TriFast. RNA was extracted and mRNA levels of (A) VEGF, (B) TRIB and (C) ATF4 were measured with RT-qPCR and normalized to $\beta_{2}$-microglobulin. Error bars represent SD of quadruplicate samples. (A, B). * Indicates statistical significance between OxPAPC treated cells transfected with ATF4 siRNA and control cells treated with OxPAPC. (C) * Indicates statistical significance between ATF4 mRNA of cells treated with OxPAPC with and without ATF4 siRNA transfection. No statistical significance was observed between ATF4 siRNA transfected cells when treated with OxPAPC, left untreated or in untreated control siRNA cells. Data were obtained in 3 independent experiments.

\section{Figure 6}

\section{CK2 inhibition by TBB reduces VEGF mRNA expression and protein secretion upon OxPAPC stimulation}

Primary RPE cells were pretreated with either TBB $(10 \mu \mathrm{mol} / \mathrm{L})$ or vehicle for 1 hour and subsequently stimulated with OxPAPC $(100 \mu \mathrm{mol} / \mathrm{L})$. Four hours later the stimulation was stopped by addition of TriFast. VEGF mRNA expression from quadruplicate samples was quantified by real-time qPCR and normalized to $\beta 2$-microglobulin mRNA levels (A). Eight hours after stimulation medium was collected for detection of VEGF protein by ELISA (B). Data were obtained from 3 independent experiments. Error bars represent SD. * Indicates statistical significance of differences between OxPAPCs stimulated cells pretreated with TBB and control cells pretreated with vehicle alone. 
Figure 1

Click here to download high resolution image

\section{Figure 1}

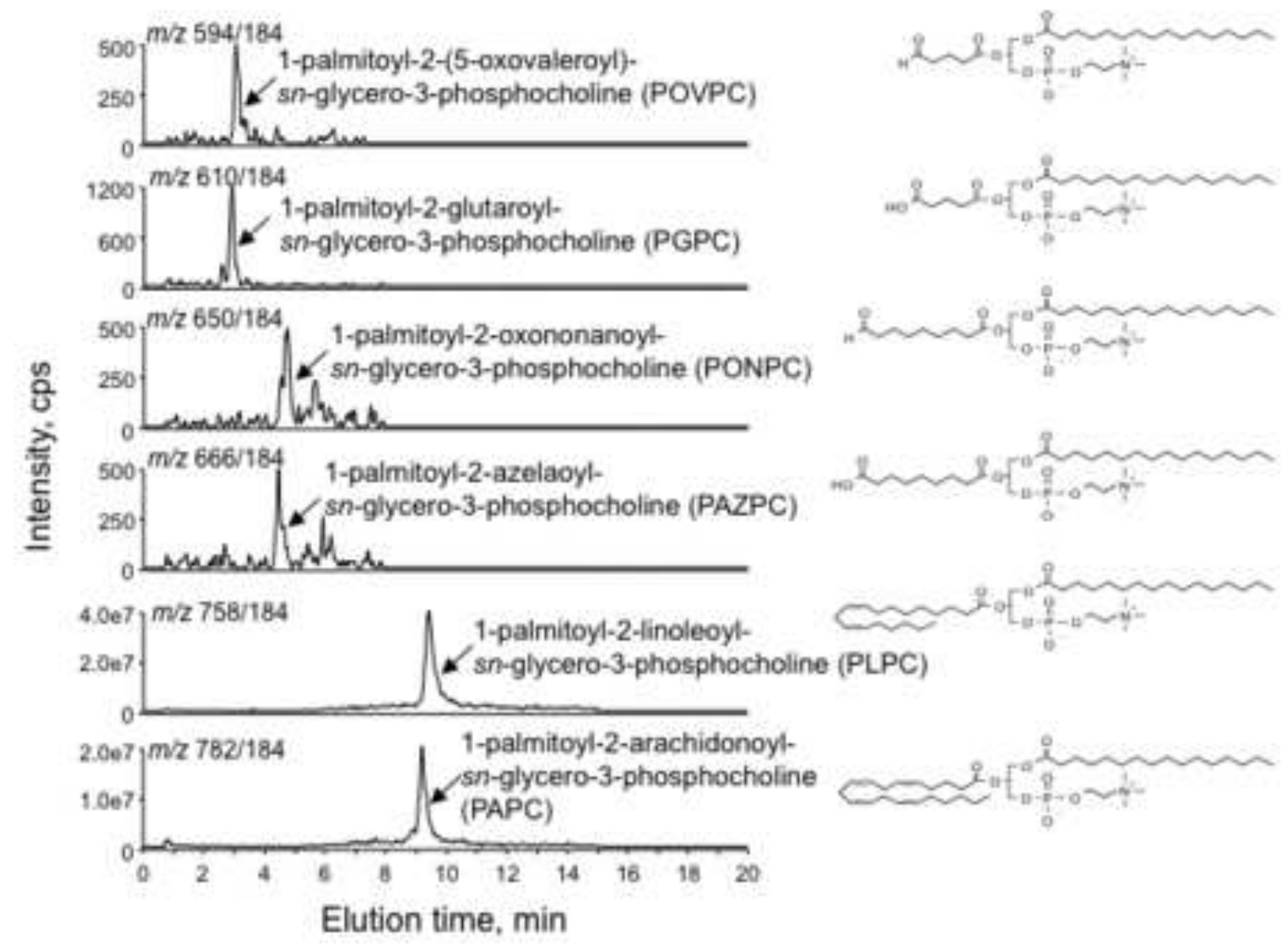




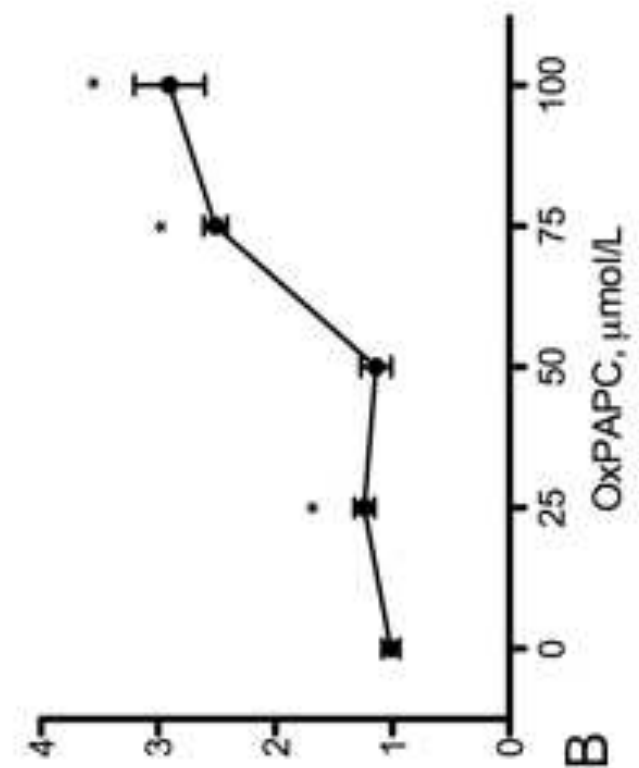

ן
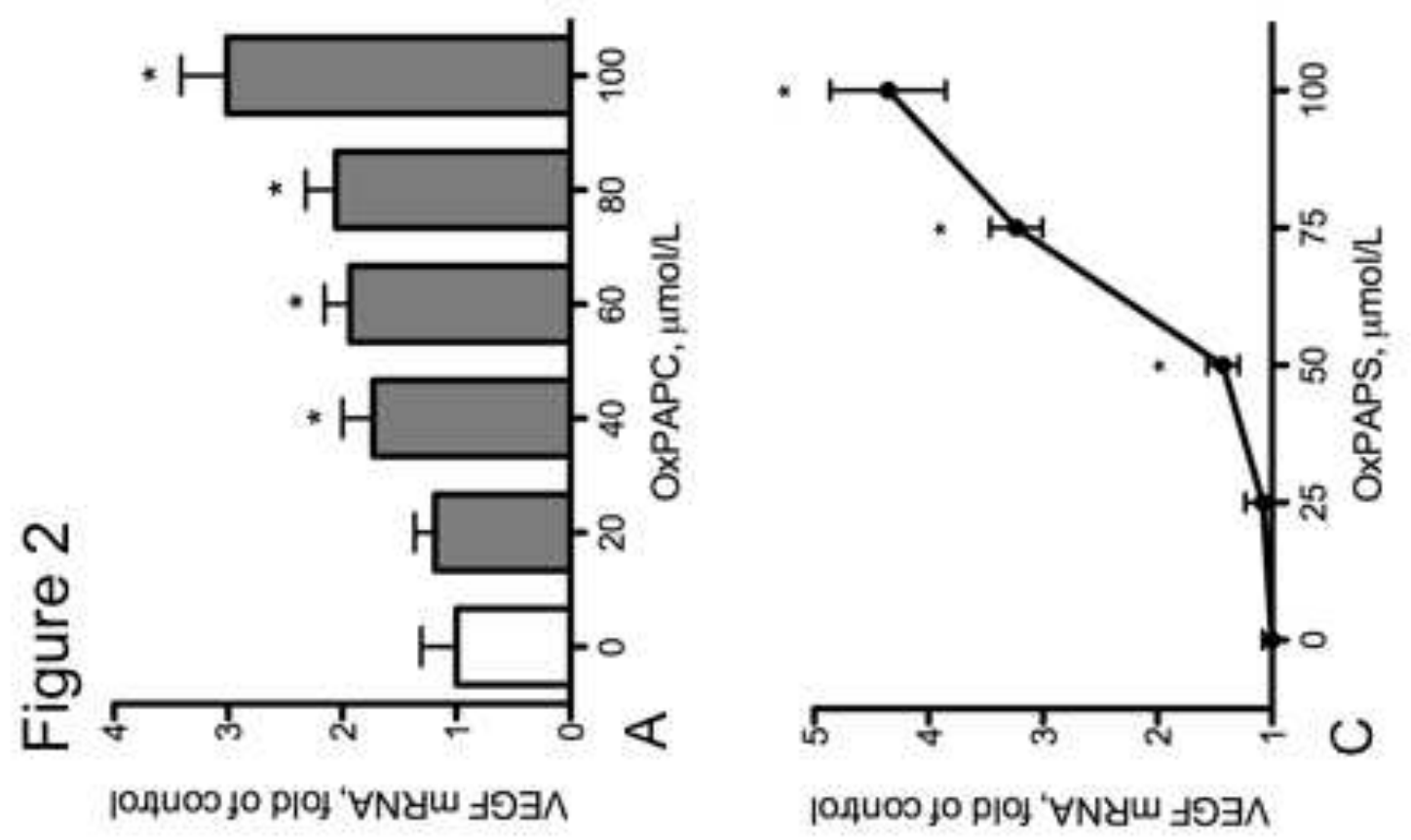


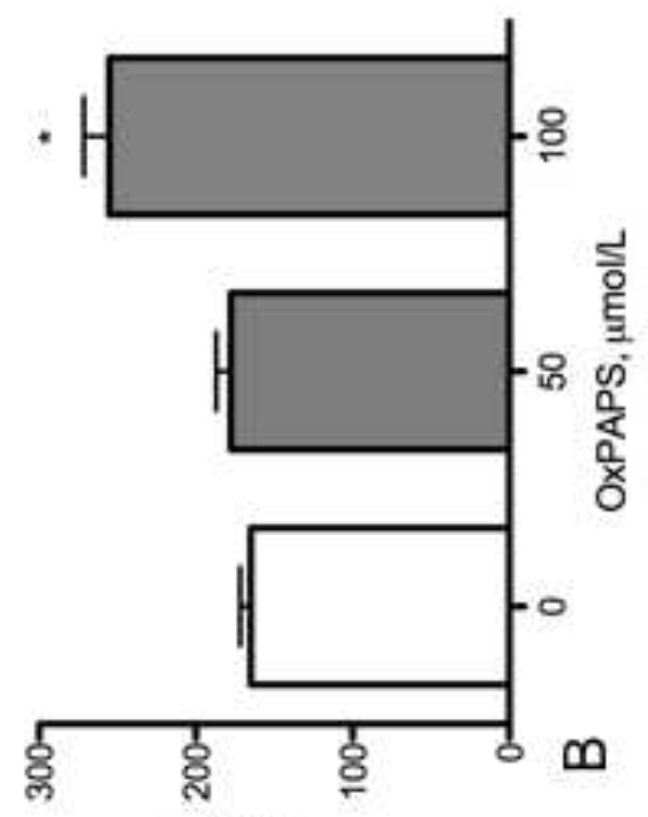

[u/6d ' $\exists 9 \exists \wedge$

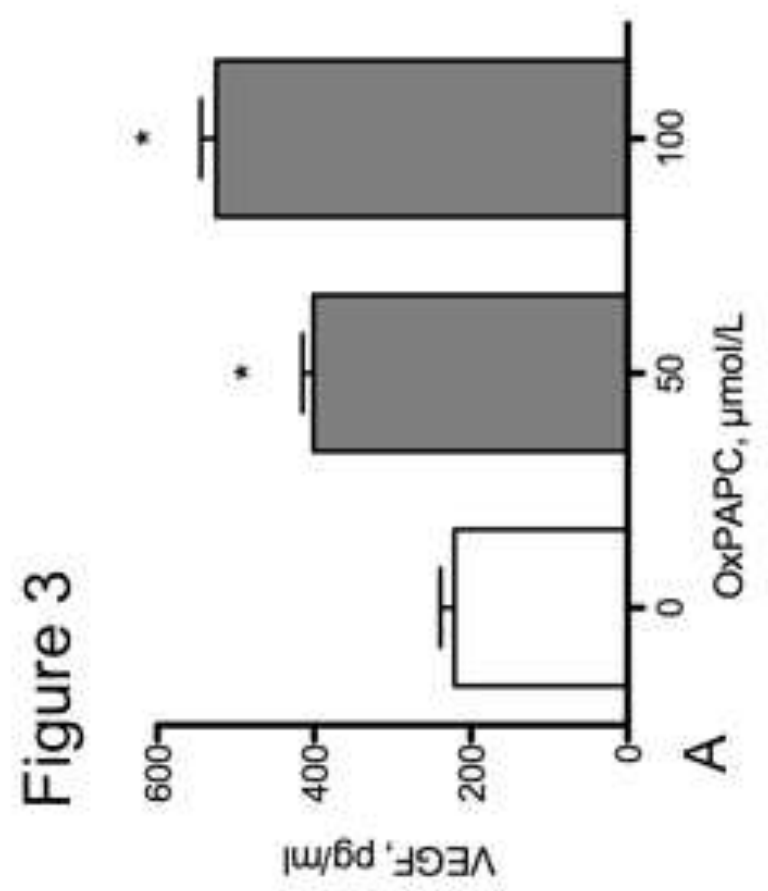

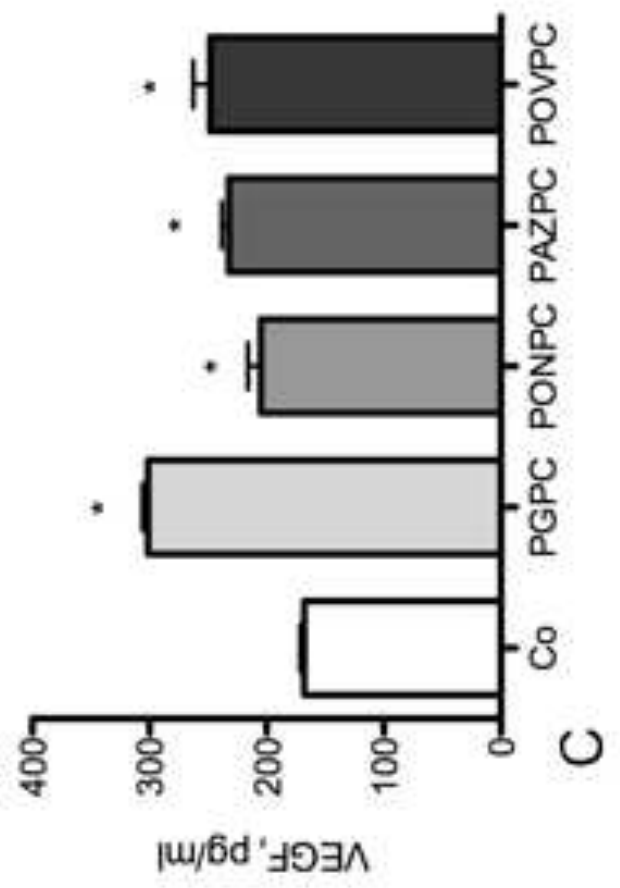

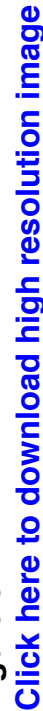




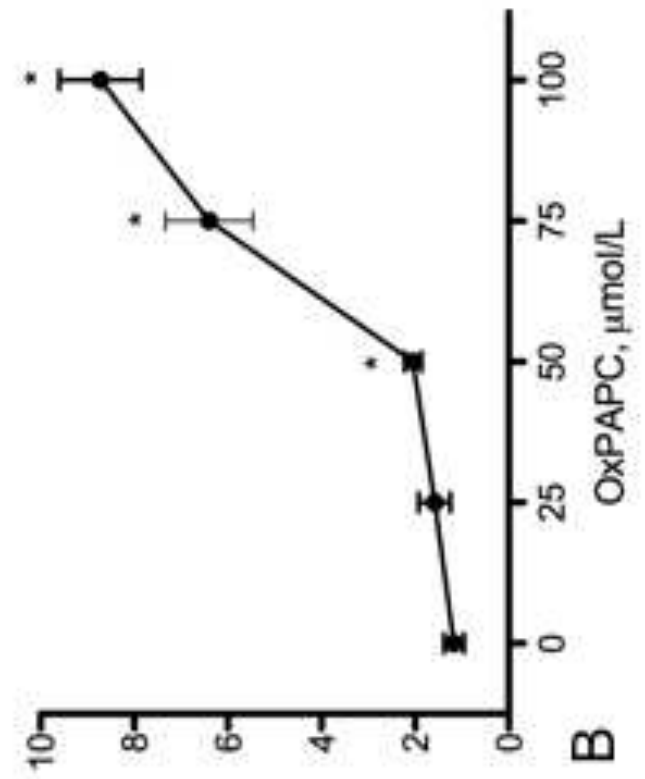

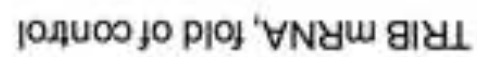

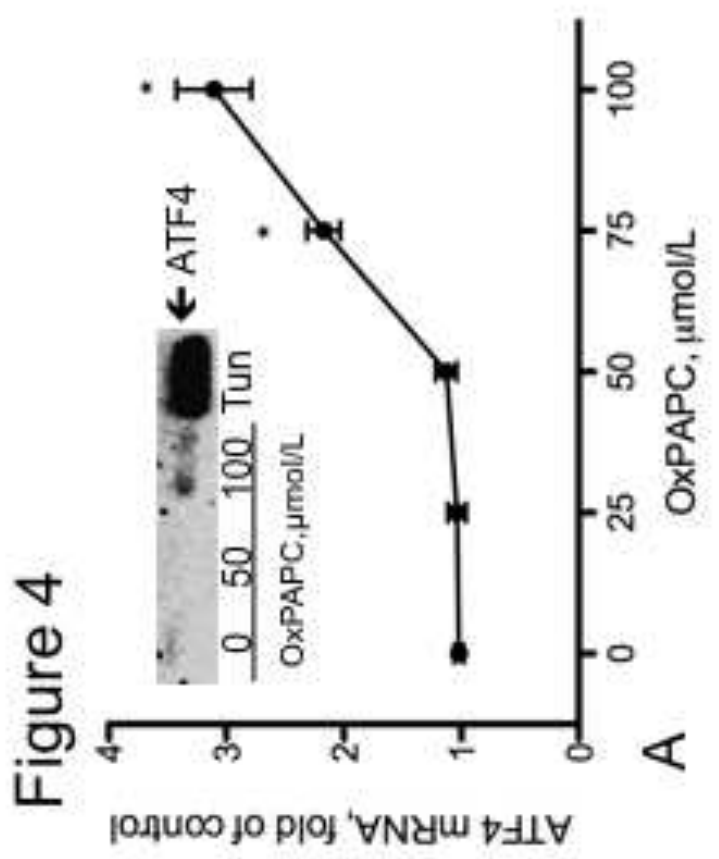

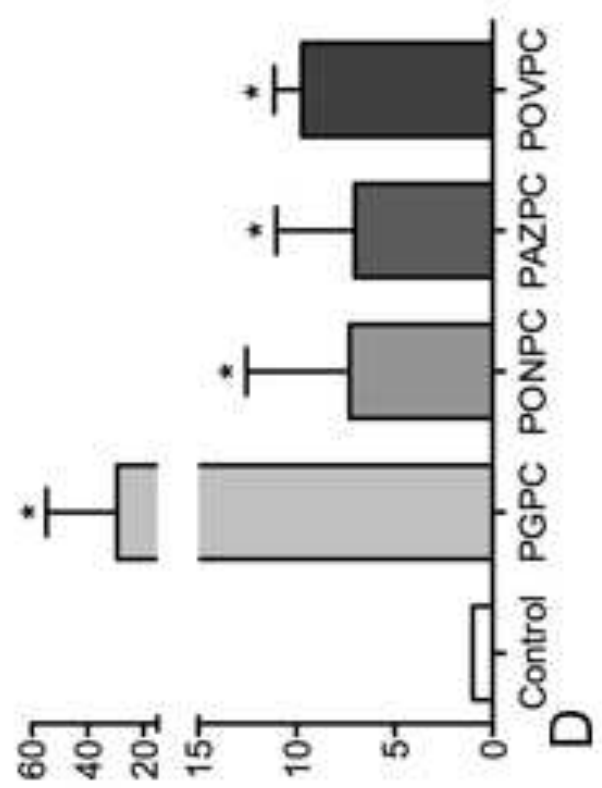

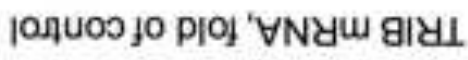

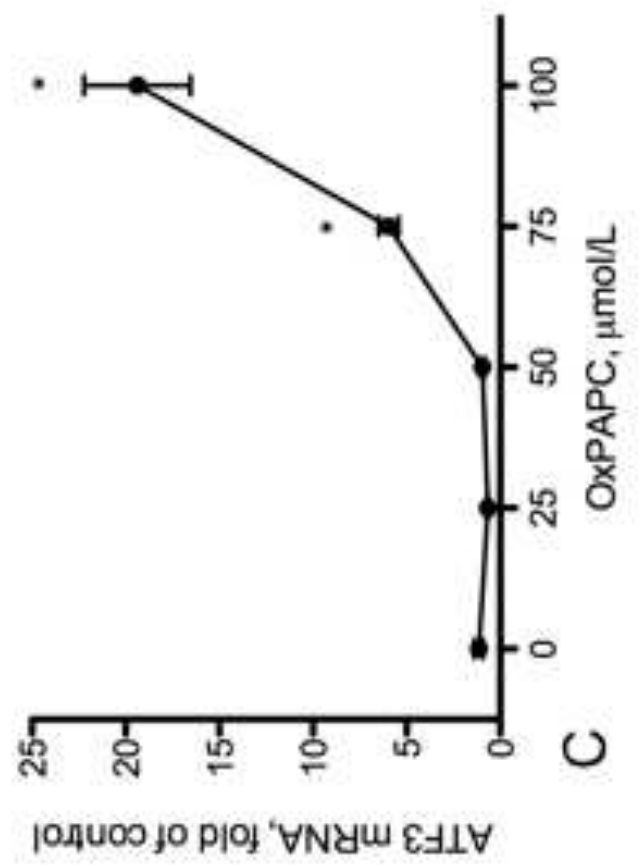



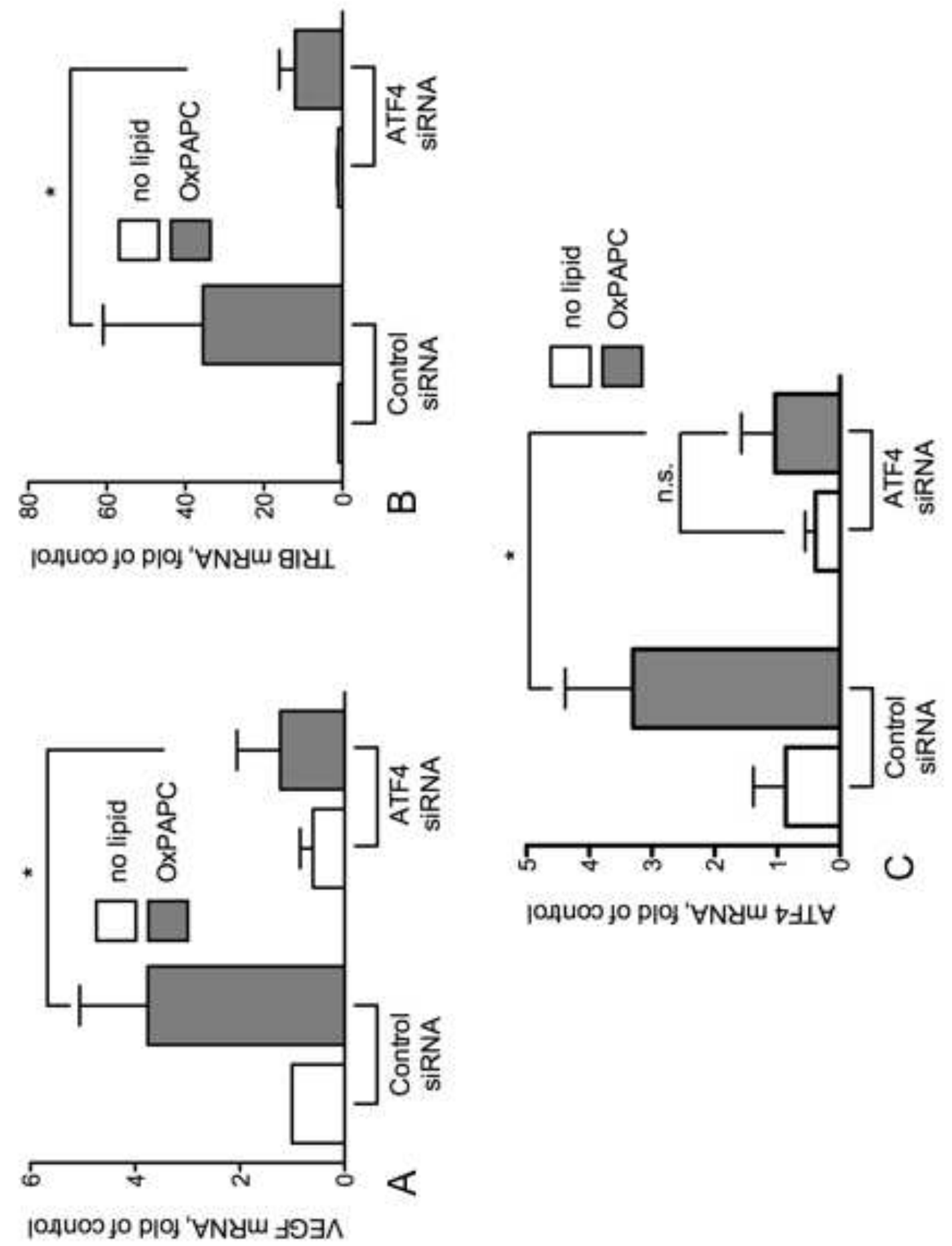

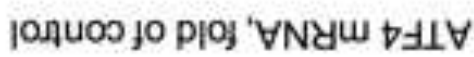




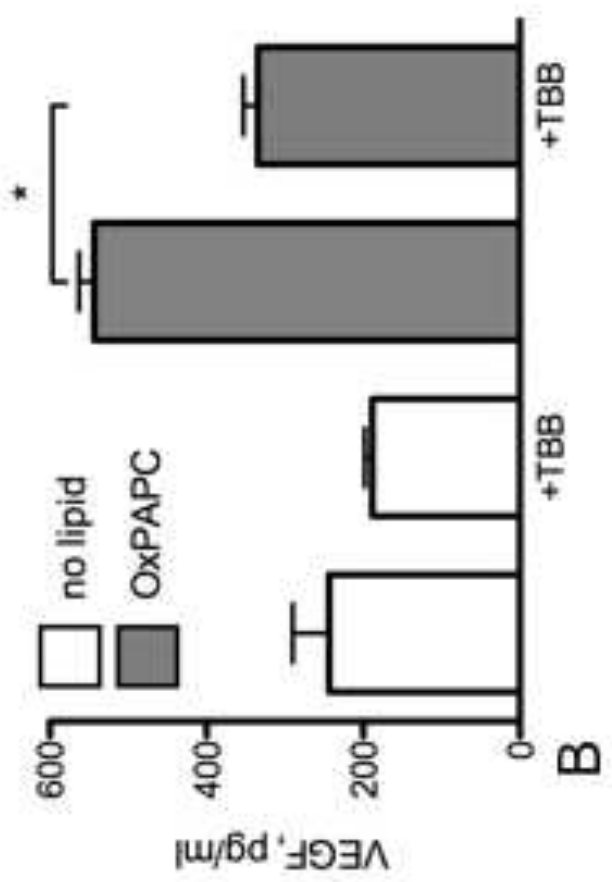

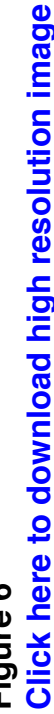

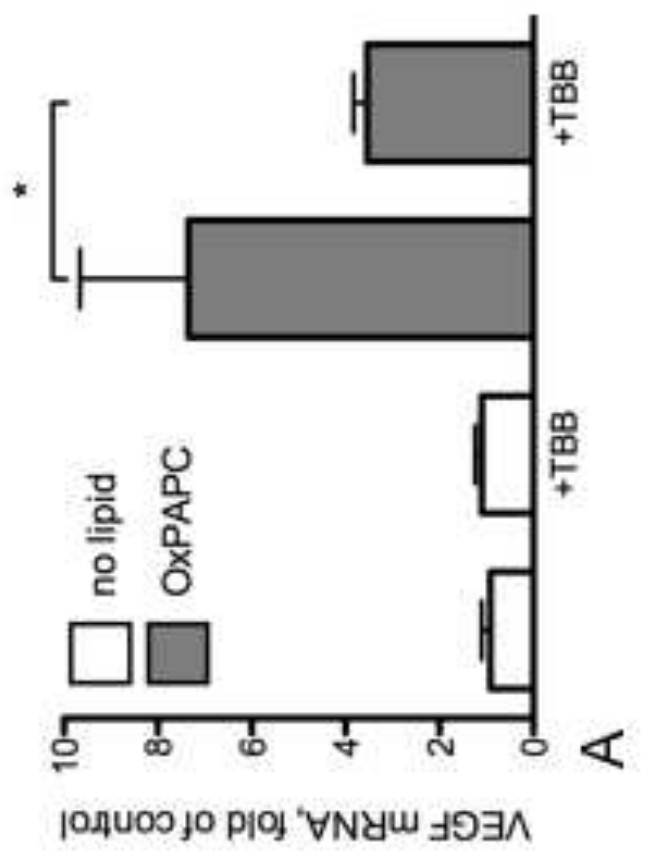

